Portland State University

PDXScholar

11-1-1995

\title{
The Use of the First Language (L1) and the Target Language $(T L)$ in the Foreign Language Classroom
}

Jeanine L. Huber

Portland State University

Follow this and additional works at: https://pdxscholar.library.pdx.edu/open_access_etds

Part of the Bilingual, Multilingual, and Multicultural Education Commons Let us know how access to this document benefits you.

\section{Recommended Citation}

Huber, Jeanine L., "The Use of the First Language (L1) and the Target Language (TL) in the Foreign Language Classroom" (1995). Dissertations and Theses. Paper 5029.

https://doi.org/10.15760/etd.6905

This Thesis is brought to you for free and open access. It has been accepted for inclusion in Dissertations and Theses by an authorized administrator of PDXScholar. Please contact us if we can make this document more accessible: pdxscholar@pdx.edu. 


\section{THESIS APPROVAL}

The abstract and thesis of Jeanine $L$. Huber for the Master of Arts in Teaching English to Speakers of Other Languages were presented November 1, 1995, and accepted by the thesis committee and the department.

COMMITTEE APPROVALS:

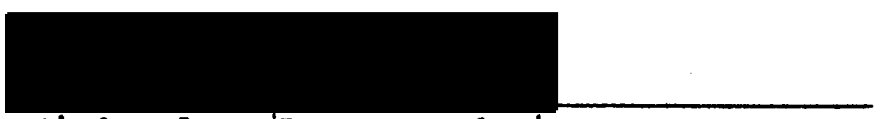

$$
\text { Kimberley Brown, Chair }
$$
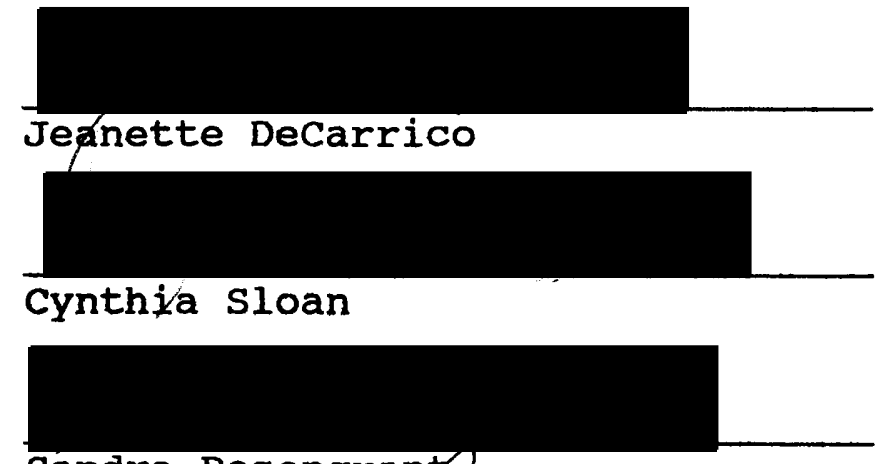

Sandra Rosengrant

Representative of the office of Graduate studies

DEPARTMENT APPROVAL:

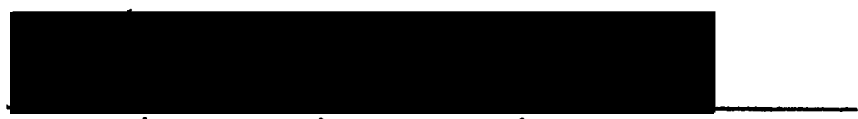

Beatrice Oshika, Chair

Department of Applied Linguistics

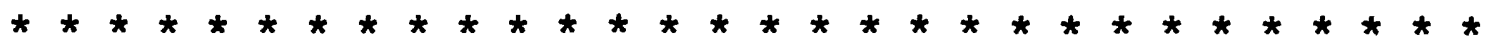

ACCEPTED FOR PORTLAND STATE UNIVERSITY BY THE LIBRARY

by

on $27 \times k$ kembet 1995 
ABSTRACT

An abstract of the thesis of Jeanine $L$. Huber for the Master of Arts in Teaching English to Speakers of other Languages presented November 1, 1995.

Title: The Use of the First Language (LI) and the Target Language (TI) in the Foreign Language Classroom

oftentimes it is the foreign language classroom that provides the basic foundation for language exposure and acquisition. In the context of the foreign language classroom there is not much exposure to the TL outside of this setting. This being the case, the quantity of the TL should be relatively high as it is an essential requisite for language acquisition. In addition, most recent research tends to suggest that high quantities of TL from the instructor is ideal.

The main purpose of this study has been to focus on university-level foreign language classrooms to explore the issue of language choice, L1 or TL, among instructors. over a ten week period, six languages were observed and audiotaped on five separate occasions. The study asked the following questions: 1) If LI (English) is used in 
university-level foreign language classrooms, what is the ratio of LI to TL?; 2) For what purposes is the LI used?; 3) What are teachers' and students' perceptions and attitudes regarding use of the $\mathrm{LI}$ in the foreign language classroom? A categorization grid was created to answer the second research question. A student questionnaire and teacher interview were administered to answer the third research question. The results were analyzed using descriptive statistics.

It was found that three out of the six languages used the L1 an average of $10 \%$ or less of the time, while the remaining three languages used the $\mathrm{Ll}$ for an average of $13 \%$ or more of the time. In regard to the second research question, four out of the six languages used the LI most freqently for the purposes of language analysis and vocabulary translation.

This investigation has attempted to explore and discuss practices within some foreign language classrooms at the university-level and to create greater awareness of those practices. 
THE USE OF THE FIRST LANGUAGE (LI) AND THE TARGET LANGUAGE (TL) IN THE FOREIGN LAANGUAGE CLASSROOM

by

JEANINE L. HUBER

A thesis in partial fulfillment of the requirements for the degree of

MASTER OF ARTS

in

TEACHING ENGLISH TO SPEAKERS OF OTHER LANGUAGES

Portland State University

1995 


\section{ACKNOWLEDGEMENTS}

I wish to thank my advisor, Kimberley Brown, for her time and helpful suggestions. 
TABLE OF CONTENTS

PAGE

ACKNOWLEDGEMENTS $\ldots \ldots \ldots \ldots \ldots \ldots \ldots \ldots \ldots \ldots \ldots \ldots \ldots \ldots \ldots$

LIST OF TABLES $\ldots \ldots \ldots \ldots \ldots \ldots \ldots \ldots \ldots \ldots \ldots \ldots \ldots \ldots$

CHAPTER

I INTRODUCTION $\ldots \ldots \ldots \ldots \ldots \ldots \ldots \ldots \ldots \ldots \ldots \ldots \ldots$

Background $\ldots \ldots \ldots \ldots \ldots \ldots \ldots \ldots \ldots \ldots$

statement of the Problem ........... 2

Statement of the Research Questions ... 4

II REVIEW OF THE LITERATURE .............. 8

Trends in Foreign Language Teaching ... 8

Features of a Language-Rich Classroom - 17

Studies of LI and TL Use Reviewed .... 22

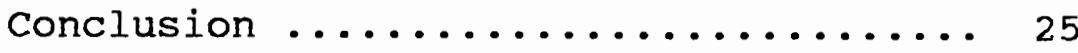

III RESEARCH METHODOLOGY ................ 27

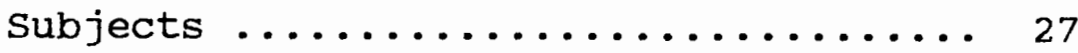

Instruments and Materials ......... 29

Procedures $\ldots \ldots \ldots \ldots \ldots \ldots \ldots \ldots \ldots \ldots . \ldots . \ldots . \ldots$

Analysis of Data ................... 35

IV RESULTS OF THE STUDY ............... 38

Ll to TL Use Results ............ 38

Purposes for Ll Use Results ......... 42 
Student Questionnaire Results ...... 54

Teacher Interview Results ........ 60

$\mathrm{V}$ DISCUSSION OF THE RESULTS $\ldots \ldots \ldots \ldots \ldots \ldots 67$

LI to TL Use Results ........... 67

Purposes of Ll Use Results ........ 72

Student Questionnaire Results ...... 77

Teacher Interview Results ........ 84

Summary $\ldots \ldots \ldots \ldots \ldots \ldots \ldots \ldots \ldots$

Limitations and Difficulties of Study . 89

Suggestions for Future Research ...... 91

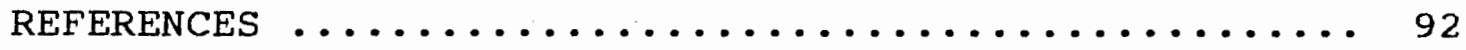

APPENDICES

A LETTER OF INTRODUCTION $\ldots \ldots \ldots \ldots \ldots \ldots \ldots . . \ldots 7$

B STUDENT QUESTIONNATRE $\ldots \ldots \ldots \ldots \ldots \ldots \ldots . . . \ldots 9$

C TEACHER INTERVIEW $\ldots \ldots \ldots \ldots \ldots \ldots \ldots \ldots \ldots 10 \ldots \ldots \ldots$

D FIELD NOTES/OBSERVATION FORM .......... 103 


\section{LIST OF TABLES}

TABLE

PAGE

I Mean Percentage of $L I$ and $T L$ Use by

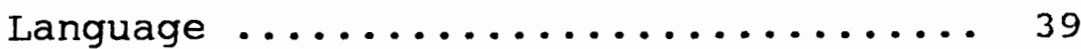

II Percentages of TL Use by Language Over Five Classroom Observations ........... 40

III Percentage of LI Use by Language over Five Classroom Observations ........... 40

IV Mean Percentages of LI Occurrences ....... 43

$\mathrm{V} \quad$ Percentages of LI Occurrences for Language A 44

VI Percentages of L1 Occurrences for Language B 46

VII Percentages of L1 Occurrences for Language C 48

VIII Percentages of L1 Occurrences for Language D 49

IX Percentages of LI Occurrences for Language E 51

$X$ Percentages of LI Occurrences for Language F 53

XI Students' Exposure to Foreign Language ..... 55

XII Students' Report of Instructors' LI Usage .. 56

XIII Students' Desired Attitudes Toward Desired English Usage by Instructor ........ 58

XIV Students' Perception of Comprehended Instructor $\mathrm{TL}$ Talk .............. 59 
CHAPTER I

INTRODUCTION

The following study explores the use of the first language (II) versus the target language (TL) in the foreign language classroom. The focus is on universitylevel classes. Data were collected over a ten week period and later analyzed using descriptive statistics.

\section{BACKGROUND}

Foreign language study is needed in today's world more than ever as we are entering an era of global interdependence. Unfortunately, little improvement has been made in boosting foreign language requirements at high school and university levels and the United States still trails far behind other nations in exposing students and citizens to learning programs leading to a working fluency in any foreign language (Brown, 1990). Since we are a nation that is for the most part monolingual, Senator William Fulbright stated that we are victims of "Iinguistic and cultural myopia" (Brown, 1990, 2). Senator Paul Simon (1980) also supports that accusation by referring to America as being "linguistically malnourished" (25). These statements reiterate the 
importance of foreign language as a valuable and necessary tool. In addition, these writers stress the importance of exposure to foreign language within the classroom as it is of optimum value.

Oftentimes it is the foreign language classroom that provides the basic foundation for language exposure and acquisition. If language acquisition is the primary goal of the learner, the quantity of the target language (TL) is particularly meaningful (Duff \& Polio, 1990). Unfortunately, there is not much opportunity for exposure to the TL outside of the classroom. This being the case, the quantity of the TL should be relatively high as it is an essential requisite for language acquisition.

\section{STATEMENT OF THE PROBLEM}

The fact that little research has been conducted in reference to language use, either $\mathrm{Ll}$ or $\mathrm{TL}$, has important implications for foreign language teachers. Not much output has been provided in the way of documented evidence that specifically addresses $L I$ and TL use, nor is there a a consensus on how much TL or LI use is necessary within the classroom, as noted by several researchers (Duff \& Polio, 1990, wong-Fillmore, 1985). The research that does exist, 
tends to suggest that high quantities of TL from the instructor is ideal. As chaudron $(1988,121)$ supports, there is a need for "high quantity, high quality foreign language input from teachers." But what really goes on in the foreign language classroom? There have been a few studies conducted to calculate the ratio of $\mathrm{TL}$ to the $\mathrm{LI}$ (eg. Guthrie, 1987, wing 1987) but they have been with secondary classes and using case study methodology. A thorough review of literature from the ten year period between 1984-1994 reveals the Duff \& Polio study as the only one that has been conducted with university-level foreign language classes. For this reason, another investigation among university classes is warranted and would contribute to general knowledge of $\mathrm{LI}$ and $\mathrm{TL}$ use in the language classroom. This study will explore what transpires within the foreign language classroom and will shed some light on how frequently and for what purposes the first language is used. This inquiry will contribute to the research of foreign language learning in regard to LI and TL use. It can open up doors to future debate and perhaps help to generate discussion and raise awareness about current practices within the classroom among language educators. 
STATEMENT OF THE RESEARCH QUESTIONS

Classroom observation was conducted to investigate the following specific questions for second year foreign language classes:

1) If $\mathrm{LI}$ (English) is used in university-level foreign language classrooms, what is the ratio of LI to TL?

2) For what purposes is the L1 used? (ie. grammar, classroom management and methodology, comprehension, and testing etc.)

3) What are teachers' and students' perceptions and attitudes regarding use of the $\mathrm{Ll}$ in the foreign language classroom?

These same questions were used in a previous study, conducted by Duff and Polio (1990) among foreign language learners at the university-level. The researchers were calculating the ratio of English to the TL in the foreign language classroom. The Duff and Polio study will provide the groundwork for the following investigation. Their research questions will be used, with minor alterations on their original study in order to make it more feasible and suitable for my purposes. Specifically, the number and frequency of classes to be observed will vary along with how the data is collected. The alterations made will yield 
more reliable data than the Duff and Polio study since they observed thirteen language classes for a total of only two hours each. This does not seem to be an adequate amount of time to gather conclusive data or make any serious claims. In comparison, this particular study will focus on six foreign language classes for a total of five hours each. This will allow more contact with instructors to observe their behavior within the classroom as well as to observe their style of teaching. The Duff and Polio study also covered such a wide range of languages (ie. Korean, Swedish, Serbo-Croation, and Uzbek etc.) that the results may not have provided much consistency. Therefore, only Indo-European languages will be used for this study--two Spanish classes, two French classes, one German class, and one Italian class. These languages also represent ones that are commonly taught at the university-level. One section in chapter two will specifically address the Duff \& Polio study in more detail. It is necessary to note that in terms of the amount of time the Il is used and the TL is used that extraneous factors may be primary determinants of the ratio. This includes curricular and institutional requirements, student expectations, and time constraints (Guthrie, 1987). In addition, the Foreign Service Institute has divided languages into four expected levels of speaking proficiency. Group I represents those 
languages which are easiest to learn and acquire, whereas Group IV represents the most difficult languages. Spanish, French, and Italian are categorized in Group I, while German belongs to Group II (Omaggio, 1986). This was taken into account when conducting the research and was reflected in the teacher interviews and student questionnaires.

The Department of Foreign Languages and Literature at Portland State University espouses a proficiency-oriented approach to language instruction. Since the instructors are working toward the same end result, proficiency, it is likely to see that the instructor will use a higher percentage of TL within the foreign language classroom than the L1 and that the L1 will probably be used $10 \%$ or less within the classroom by the instructor. One researcher (Akinson, 1987) has found the ratio of 5\% L1--95\% TL to be very profitable to learners in his classroom. This supports the statement of "high quantity input from teachers" that Krashen spoke of (1982). I chose 10\% LI use by instructors because it is a more conservative figure than the 5\% advocated by Akinson. Of course it must be noted that each class is a unique setting, but in general it is hoped that the foreign language instructors in this study will be using high quantities of TL.

Based on the Department's committment to proficiency based teaching it is likely to see a certain stance 
adopted. This suggests that the LI in the foreign language classroom will probably be used most frequently for the purposes of language analysis and vocabulary translation by the instructor. A greater percentage of time will also be spent on these categories. Though the LI should not be abused within the classroom, some teachers see the LI as a potential tool and resource, for example to save time and prevent confusion (Auerbach, 1993). It would also be unrealistic to expect instructors to avoid using the LI. 
The following chapter is a review of literature relevant to this investigation. Trends in foreign language instruction are reviewed and summarized to provide an understanding of the different types of classroom methodologies and approaches in regard to LI and TL usage. Features of a language-rich classroom environment are touched upon to illustrate the need for a high degree of TL exposure. Finally, a review of foreign language studies that have been conducted to compare TL use versus LI use are discussed in more detail and provide support for the need of the following investigation.

\section{TRENDS IN FOREIGN LANGUAGE TEACHING}

\section{Past trends in foreign language teaching}

The question that has been posed quite frequently throughout the history of foreign language teaching has been how much the LI should be utilized within the classroom and has often been the root of heated debate. The use of $\mathrm{L} 1$ in the foreign language classroom has been "emphasized, banned, required, and barely tolerated" 
(Prator, 1991, 11). Especially in the past the ability to speak the TL was often irrelevant as the TL was learned for interpreting text or literature but not for communication. The history of foreign language teaching, in regard to methodologies or approaches, has been marked more by controversy than by consensus. In fact, reviewing the Iiterature on the history of language instruction sheds light on the diversity of methodologies that have been created and endorsed. As Omaggio (1983) states, the teaching profession has been involved in a progression of "revolutions" to reach an agreement on the "one true way" to teach a foreign language. In the face of all of this controversy and factions the common goal shared by the majority of language educators has been to seek new and improved ways to facilitate and increase language learning. Following, is a brief overview of past methodologies and approaches utilized within the foreign language classroom during the twentieth century. only the major orientations that have had a considerable impact within the language profession will be highlighted.

Methods:

Grammar-Translation Method

This particular method was based on the method to teach classical languages, such as Latin and Greek, to the teaching of modern languages. This method became quite 
popular in the late eighteenth century but has occurred in language instruction throughout the ages (Stern, 1983). Foreign language use was taught in the students' LI--direct translation being the framework for learning the new language. The goal was often not oral or aural proficiency. The fact that the language was conducted in the II was unimportant and more applicable to the learners' needs at that time since the TL was not used as a means of oral communication, but rather used for literary or scholastic purposes. Currently this method, if used at all, is utilized in conjunction with other methods, but not as the principle technique (Benseler, 1980). The GrammarTranslation method has been used as a small part of the lesson, especially for the less commonly taught languages.

\section{Direct Method}

This method represented a shift from the literary language to spoken everyday language and was a reaction to the failure to produce learners who could use the foreign language they had been studying (Celce-Murcia, 1980). As one source states (Bloomfield, 1942, 45):

$$
\begin{aligned}
& \text { Our schools and colleges teach us very little } \\
& \text { about language... some teachers have not } \\
& \text { sufficient command of the foreign language. often } \\
& \text { enough the student, after two, after three, or } \\
& \text { after four years of instruction cannot really use } \\
& \text { the language he has been studying. }
\end{aligned}
$$

This method avoided the II and translation as technique. In this, it was radically different from the Grammar- 
Translation Method. Rather, the use of the TL was used as means of instruction and communication. For this reason, the direct method necessitates native or near native command of the TL by the teacher since the LI was not encouraged. This method was most popular during the 1850s-1900s (Benseler, 1980).

\section{Reading Method}

This approach was created in reaction to the direct method and its nonfunctionality (Richards, 1986). Reading was deemed the most practical skill. Besides, many teachers did not know the foreign language well enough to utilize the direct approach. With this approach, the II was not banned. Students were trained in reading comprehension and vocabulary was emphasized. This method was created around the 1920 s and 1930 s.

\section{Audiolingualism Method}

This method perhaps had the greatest impact on the language world (Hosenfeld, 1979). It became the method of the 1950s and 1960s. The main tenet for audiolingualism was the separation of the four skills--speaking, Iistening, reading, and writing, with the main emphasis on the first two. This method was characterized by mimicry, memorization, and pattern arill because it was the assumption that language was habit formation, which was based on behavioristic theory (Diller, 1975). Like the 
direct method, II use was not advocated. Though the instructor was responsible for conducting the language lessons in the TL, it was not necessary for the instructor to be proficient as 1 ong as the structures and vocabulary being reviewed were known. This is because the materials and activities were very controlled. Yet because one of the main tenets of Audiolingualism was accuracy in speech, it was necessary for the instructor to have very good pronunciation. Otherwise, native speaker tapes were often used.

\section{Cognitive Approach}

This approach came about in response to the main criticism against the audiolingual method, that language is habit forming. Instead, the cognitive approach viewed language learning as a creative activity using mental processes in a conscious, analytical manner that focused on rule acquisition (Hosenfeld, 1979). Grammar was highlighted again, as well as reading and writing. The teacher was to be proficient in the TL as well as being competent in the analysis of the TI. Because inductive methods of presentation of, for example, grammar points were used, the codes for prompts were consistently in the TL. Il use was reserved for clarification. Current trends in foreign language teaching The support for the past trends in Ianguage 
instruction, especially the audiolingual method, soon died out as spectacular results were not being achieved by these methods. 1965 through 1970, were especially marked by controversy within the foreign language profession in a renewed search for a more adequate basis for language teaching. Language instructors relied less on one single method on which to base their teaching methodology. Instead, features from the various methodologies were combined to create an approach that was unique to each individual classroom. This was frequently referred to as eclecticism which created more diversity within the teaching profession (Diller, 1978). This shift was a major change in that over a century, language educators had tried to solve the dilemma of language instruction by concentrating almost solely on teaching "method" (Stern, 1983). The new approaches that gained recognition and came into favor will briefly be described below.

New Methods:

Affective-Humanistic Approach

This approach was the result of language educators focusing on the often neglected dimension of learner anxiety. New ways were researched to induce learner readiness by providing a relaxed, non-threatening environment (Moskowitz, 1978). Meaningful communication was emphasized, as students worked in pairs or small groups. 
The teacher's role was as facilitator. The teacher was to be proficient in the TL though initially the LI and TL were frequently used for translation to help students relax.

Comprehension-Based Approach

This approach was created on the assumption that language learning parallels to a high degree first language acquisition (Winitz, 1981). This being the case, Iistening comprehension was viewed as the most important and basic skill to develop. The other skills would naturally develop over time, as they did with first language learning. Students were encouraged to speak only when they were ready and until then, to respond nonverbally. Rule learning and error correction were de-emphasized. If the teacher was not a native speaker, other materials, such as audiotapes, were to be available to maintain a high level of input because the TL was highly stressed. Use of the II was not encouraged. The main criticism against this approach is that it did not equip learners with survival skills and was too general (Blair, 1982).

\section{Communicative Approach}

The main tenet of this approach has been that the goal of language is communication in the TL. This reflected the social view of language use which unlike chomsky's theory of Iinguistic competence, was characterized by "rule-governed creativity" (Diller, 1975 ). 
Materials and activities were to be as authentic as possible and reflect "real life situations and demands" (Celce-Murcia, 1980). The teacher was to be fluent in the TL and to use it appropriately. The II was not banned, yet it was to be minimally used as the main goal of language teaching was communication.

Conclusion

These sketches of methods throughout the past century have so much as set an agenda regarding the use of the TL and the Ll within the foreign language classroom. The use of the TL and the LI has waned or increased depending on which method was currently in favor. For this reason it was necessary to tentatively review the past and current trends within the foreign language classroom to get an idea of the historical timeline and its influence on language choice. It also should be noted that because of the underlying weakness of the method concept, that currently the common belief has circulated that language teaching cannot be "conceptualized" within the constraints of teaching method alone nor can we suscribe to only one method. As Strasheim (1976) has pointed out, we will have to learn to deal with "working hypotheses" rather than "one true way" for we are moving out of the period dominated by absolutes.

It is necessary to address one issue that some 
Ianguage educators have stressed. It is the notion that in the early phases the learners be allowed to respond in the II first and then the TL as it moves them. They believe that TL responses are only to be encouraged when a learner's "self-image and ease" in the classroom is such that a response in the TL will not cause anxiety (TerrelI, 1982). This idea reflects the psychological aspect of language learning by consciously acknowledging the L1 of the learners. When the literature does not formally address the use of the $L 1$, it seems to indicate that there is "benign-neglect" of the Ll. This may not even be a conscious act, but rather a by-product. Also when the Iiterature does not formally address the LI, several messages are perhaps being sent-- that the LI has been relegated to a lesser degree, that it is not valued, or maybe that the $\mathrm{LI}$ is viewed negatively. It should be the responsibility of language educators to address these issues and ideas in regard to language learning, especially in the TESOL (Teaching English to Speakers of other Languages) context because it is often a heterogeneous environment, where students are learning in a non-native setting. Yet, within the foreign language context it can generally be assumed that there is homogeneity within the classroom in reference to a common shared language and culture among the learners. In 
addition, because the foreign language is being learned in their native country, the students are not being deprived of their language.

\section{FEATURES OF A LANGUAGE-RICH CLASSROOM}

The most successful adult second language learning is achieved by immersion in the TL environment, where one is forced to communicate for survival (Brown, 1987). This is because language should be acquired functionally, rather than through formal instruction, according to some educators (Richards, 1986). On the basis of the observation that language study outside of the classroom seems to generally be more successful than formal study within the classrooms, some scholars have advocated a "deschooling of language instruction" (Politzer, 1980). However, this is quite unrealistic and impractical for many people, especially for adult learners where total abandonment of formal language teaching in favor of "immersion" may not always be the best strategy. This being the case, the classroom should function as an environment which promotes language acquisition. Krashen (1982) who has advised language teachers, stresses that this should be achieved by providing comprehensible input and a sufficient quantity of the TL. Many teachers will rely on the students' Ll to save time and to help with 
comprehension, yet Ellis (1984) stresses that the students are then deprived of valuable input in the TL. This use of language should be not only for instructions and drills, but also disciplinary and management operations. If the language is to be taught exclusively in the TL, it must be made comprehensible to the learner. This will then enable the learner to make significant advancement toward proficiency. It will also provide a rich TL environment that serves multiple functions for the language learner. Not only should the teacher be producing large quantities of the TI, but the learner should be doing so also. A hypothesis that has been developed in reference to learners states that progression is facilitated by generating language more frequently. This idea has been expressed in the "comprehensible output hypothesis" with the following statement (Swain, 1985:248):

One function of output is that it provides the opportunity for meaningful use of one's linguistic resources. Smith...has argued that one learns to read by reading, and to write by writing. Similarly, it can be argued that one learns to speak by speaking.

Similarly, listening comprehension is important in a classroom which provides tremendous amounts of meaningful Iistening practice. As one language educator states, (Kalivoda, 1988) "satisfactory teacher talk" does not simply consist of speaking without consideration for 
student comprehension. What is needed to ensure understanding is teacher talk which is suited to the students' level. This can also be referred to as "comprehensible input" (Krashen, 1982). As long as comprehensible language input is being provided by instructors, they are aiding natural language acquisition. Natural language encompasses comprehensible input provided by instructors in everyday exchanges in the classroom setting that are communicative in nature, from providing instructions to relating personal anecdotes in the TL (Omaggio, 1983). The proficiency oriented classroom is one in which such natural acquisition chances are manipulated to the fullest extent possible. One language educator's own personal experience shows that acquisition of the listening comprehension skill is the key to developing language proficiency (Belasco, 1983). The proficiency-oriented approach has assigned several priorities to language teaching. They include: I) having opportunities provided for students to practice using the TL in a range of contexts that simulates the target culture; 2) having opportunities provided for students to practice carrying out a range of functions that would be used in dealing with others in the target culture;

3) concern for the development of linguistic accuracy from the beginning of instruction; 4) ackowledgement of the 
affective needs of students, as well as cognitive needs; and 5) fostering of cultural understanding so students are more prepared to live in the TL community (Omaggio, 1983). Moscowitz's (1976) findings from former foreign language students have demonstrated that the use of the TI in the classroom is an essential characteristic of outstanding teachers. Comparable findings in Warriner's (1980) identification of a good foreign language class shows that the TL is used almost entirely by both teacher and students. Students seldom use the LI and teachers use it only infrequently for brief explanations with quick reversion to the TL for practice. Not only should the TL be used almost exclusively in the advanced classrooms, as other sources argue, but it should be utilized within the beginning classrooms as well. Not developing a sustained TL environment may be detrimental. Secondary school teachers who have allowed students to speak in the LI in the beginning stages of instruction report learner reliance on it (Kalivoda, 1983). However, regardless of what language the student chooses to utilize, for that is a separate issue warranting another investigation, the point that needs to be stressed is that instructors should continue to provide a rich TL environment regardless of the class level. Instructors can greatly influence language learning by the way they use language in instructional events and 
by the opportunities they make available to students during these events to practice the TL (Wong-Fillmore, 1985). since the oral climate of the classroom is under the control of the instructor it is imperative that the instructor establish a model of comprehensible and sustained TL use for the students to follow (Davies, 1982). Emphasis should be placed on oral TL usage from the beginning of the course to set an agenda and to establish a classroom setting that works to combat the lure toward L1 use. Constant shifts between TL and LI usage leads to the undoing of a meaningful learning environment. When learners can rely on obtaining the information that is being communicated to them in the LI, the language they already know, they do not find it compulsory to pay attention when the TL, the language they do not understand, is being used (Wong-Fillmore, 1989). Observations in classrooms where this method has been used have shown that students tend to tune out when the language they do not know is being spoken (Legarreta, 1977). One suggestion from an instructor to combat language shifts is to provide a 10 minute safety valve at the end of the class hour to answer students' questions or to clarify points that have not been understood (Shrum, 1985).

As one researcher notes (Chaudron, 1985), much more observational and especially experimental classroom 
research is necessary to determine what aids learners' comprehension, and how that comprehension and subsequent practice leads to greater TL competence.

STUDIES ON LI AND TL USE REVIEWED

Three specific studies that have addressed the issue of II and TL use within the foreign language classroom will be briefly reviewed. The Duff and Polio study (1990) and the Guthrie study (1987) both have focused on university-level foreign language classes, while the wing study (1987) has researched secondary classes.

\section{Duff and Polio study}

This study is the one on which I am basing the following investigation. It was conducted at the University of California, Los Angeles in the 1988-89 academic year. The researchers' basis for the investigation was to explore what goes on within the foreign language classroom since there has not been much literature relevant to the topic of LI and TL use. They were arguing for high degrees of TL use by the instructor, as it aids language acquisition. Thirteen second-year language classes were used in the study. All of the instructors were teaching assistants, as well as native speakers of the language being taught. Two fifty-minute sessions of each class were observed and audiotaped. The 
language classes selected were from the East Asian, German, Near Eastern, Slavic, and Romance Languages. The guiding question of the study was to find the ratio of $\mathrm{L} 1$ to TL use. In addition, student questionnaires and teacher interviews were conducted to supplement the research.

The results of the $\mathrm{Ll}$ and $\mathrm{TL}$ use by the teacher ranged from $100 \%$ TL use all the way down to $10 \%$ TL use, with $67.9 \%$ being the average for $\mathrm{TL}$ use for the thirteen classes. The L1 use ranged from $90 \%$ to $0 \%$, with $32.1 \%$ being the mean for L1 use. The variability of TL and LI use among the classes has made it difficult to make any generalizations about language usage and the researchers admitted to the inconsistency of the results found. The authors of the study also stated that their method used to quantify the data needs to be validated. In conclusion, the study reiterated the need for high TL use within the language classroom and commented that more research should be done in the future addressing the issue of language use.

\section{Guthrie study}

This study was done as a case study involving six foreign language classrooms. The basis for the researcher's study was to examine three conditions that she believed represented optimal linguistic input. They were: 1) high usage of the TL 2) high incidence of student 
talk and 3) high proportion of the class activities in which "appropriate student performance depended on the understanding of the content of classroom discourse" (17). For relevancy to my topic, I will only focus on the results of the LI and TL use. The classes observed were all French, second semester classes. Each was observed, both audio- and videotaped on two separate occasions. The results of TL use ranged from $98 \%$ to $59 \%$, with $85 \%$ being the average. The L1 use ranged from $41 \%$ to $2 \%$, with $15 \%$ being the average of $\mathrm{Ll}$ use within the foreign language classes. This study showed more consistency than the Duff \& Polio results, but because it was a case study, with the classes being observed only twice, the results are not very generalizable.

In conclusion, Guthrie found for the most part high degrees of $\mathrm{TL}$ use among the classes. In relation to the other aspects being examined, she noted that there was a much greater "lack of convergence" than had been expected. She also reported that more research is needed to explore and understand optimal language-acquisition environments.

\section{wing study}

This study is relevant in that $\mathrm{L} 1$ and $\mathrm{TL}$ use is calculated, but it must be noted that only secondary classes were used. The researcher was advocating high degrees of TL use by instructors, especially when adjusted 
appropriately to the situation because it provides an environment in which students can make considerable progress toward proficiency in the TL.

Fifteen second year spanish classes were sampled. The data were generated from audio recordings of three class sessions gathered over a four month period. Not only was the researcher calculating the ratio of L1 to TL use, she also was examining the function of the TL as either linguistic or communicative. Linguistic competence refers to the ability to understand and produce the phonological, morphological, syntactical, and lexical elements of language whereas communicative competence is defined as the capacity to send and receive messages (161).

The results of the TL use reported by wing were a mean of $54 \%$ and a mean of $46 \%$ LI use in the Spanish classes. This study did not offer a complete breakdown of individual averages of $\mathrm{LI}$ and $\mathrm{TL}$ use. In conclusion, Wing argued for high degrees of TL use. She also stressed the need for more studies to explore the use of the TL, especially in relation to what students' roles are in LI and TL use, and whether extensive use of the TL encourages or inhibits student participation.

CONCLUSION

This review of Iiterature has provided an overview of 
past and current trends in foreign language teaching in order to examine how methodologies have influenced language choice, features of a classroom with high quantities of TL input, and current relevant studies that have been conducted which have focused on the L1/TL ratio. AII of these areas have been considered to some degree in this study's research methodology and analysis of data which are detailed in the following chapters. 
CHAPTER III

\section{RESEARCH METHODOLOGY}

The research methodology chosen for this study was classroom observation. The method was chosen as it was the object of the study to investigate specific questions concerning teacher use of both the first language (LI) and target language (TL) within the foreign language classroom that could only be answered through direct non-participant observation. Data gathering techniques consisted of audiotaping each individual class, coding and transcribing the data, and later calculating L1/TL ratios, interviewing and analyzing data from student questionnaires.

\section{SUBJECTS}

\section{Recruitment of subjects}

The subjects selected were those who were available and currently teaching foreign language classes during winter term at Portland State University. Random sampling was not feasible since the actual number of foreign language classes offered in one university is low and I was only able to research those classes who were willing to be observed. Only second-year foreign language classes were selected. This meant that the students had had at least 
one term prior to the class.

A letter of introduction was sent along with a brief description of the study to the teachers I wished to observe without revealing the specific research questions I wished to answer (see Appendix A). The letter requested permission to observe and audiotape classes, to conduct teacher interviews, and to administer a brief student questionnaire. The teacher was asked to respond with a telephone call if possible so that a meeting of introduction could be arranged.

\section{Description of subjects}

I was able to secure six foreign language classes to observe during the course of one term. Each class was observed in fifty minute to one hour increments for a total of thirty observation hours. Each class was observed for approximately five hours each.

only Indo-European languages were used for this investigation, primarily because some of the so-called "critical languages" which are not Indo-European may not be taught the same way with the same methodologies (stern, 1983). Consistency was important, as the Duff and Polio study covered such a wide range of language types that the results were not very cohesive. Two Spanish classes, two French classes, one German class, and one Italian class were used in this study. To insure protection of the 
teachers the classes will be labelled Language A, Language $B$, Language $C$, Language $D$, Language $E$, and Language $F$ throughout the paper. The letters do not match the classes listed above in that particular order.

All of the classes, except one were taught by teaching asssistants (TAs). The instructor for Language $D$ was hired as a foreign language instructor. The gender breakdown was four females and two males. Of those six instructors, only two were American.

\section{INSTRUMENTS AND MATERIALS}

\section{Categorization Grid}

Each class was audiotaped with a microcassette recorder and the relevant information was transcribed. This included all of the Ll utterances. A categorization grid was drawn up in reference to research question 2) "For what purposes is the LI used?" The nine categories that were used include:

1) negotiation of syllabus and lesson

2) classroom management

3) language analysis/presentation of rules (including grammar, phonology, and spelling)
4) instructions or prompts
5) explanations of errors
6) assessment and comprehension checks 
7) maintaining social relations

8) vocabulary translation

9) other

The first six categories came from the Polio article (1994) and the last three categories were created by me. The appropriate category was marked within the categorization grid for each time it occurred. The advantage of an observation system with clearly defined categories was its reliability and objectivity because it had the ability to reveal patterns that might otherwise go unnoticed (Nunan, 1989). I was able to focus on specific events that would provide quantifiable data.

The nine specific categories were chosen and adapted from Polio's (1994) list of reasons for why teachers fall back on the Ll. She suggested that when teachers do utilize the Ll, it is often for 'grammar analysis', 'classroom management', or 'instructions' etc. I felt additional categories were needed such as 'maintaining social relations' and 'other' to make the list more comprehensive and to cover all of the possibilities for what purposes instructors used the Ll.

\section{Student Questionnaires}

A questionnaire was used for the students of the six foreign language classes observed. This instrument comes 
from the Duff and Polio study and is in Appendix B at the end of the paper. It consisted of six questions. The intent of the questionnaire was to uncover students' perceptions and attitudes regarding the use of the LI in the classroom. It also requested basic demographic information, such as the status of the student (graduate or undergraduate), the age of the student, and the major of the student.

\section{Teacher Interviews}

The teacher interviews utilized for the research were also a Duff and Polio instrument and are included at the end of the paper in Appendix $c$. The purpose of the interview was to gain insight into the teachers' roles and to give them an opportunity to clarify what activities and methodologies they utilized within the classroom, what their opinions were of LI versus TL use, and how they perceived their students' needs and abilities. The interview also asked for the teachers' particular area of specialization and how much experience they had. In addition, many casual interviews in the form of conversations occurred spontaneously with the teachers during class breaks and after classes.

PROCEDURES 
Before conducting the research it was arranged with the class instructors beforehand which classes were to be observed. Two of the instructors made it known that they were not interested in setting up specific times and that I was to come whenever it was convenient to me. I still made it a point to let those instructors know a week in advance which day I would observe. To get an accurate assessment of the classroom daily events, I made an effort to set up observations with prior knowledge of what would be taught. It was important to observe a variety of activities within each language to get a representative picture. To keep things consistent, an attempt was made to schedule observations to each class (A, B, C, D, E, F) within the same week and to spread those observations out over the ten week term. For the most part, the classes were observed during week 2, week 3 , week 5, week 6 , and week 8 of winter term. The last two weeks were not chosen as the instructors were preparing for finals and wrap-up work.

At the beginning of each new class to be observed, the students were told briefly about the study and were asked to sign the informed consent form. No instructions were given to them, as I was not specifically observing their behavior, only the teacher's. Only their cooperation was needed in completing the student questionnaires at the end of the fifth observation. 
In each of the foreign language classrooms, I tried to be as inconspicuous as possible. This was achieved by sitting in the back of the classroom. This vantage point offered a clear view of all of the students and the instructor. Only in one class was I unable to sit towards the back. Language $F$ was filled to capacity and no seats were available in the back. Sitting on the side, towards the front was enough out of the way to remain somewhat distanced from the class.

The microcassette recorder was placed in the front of the room, close to the teacher during every observation for optimum recording. Since the study was only observing the teachers' use of the L1 and TL, it was not important to capture any of the students' talk.

During each observation, general field notes were taken. A basic field notes/observation form, from the Duff and Polio study was used to $\log$ in the classroom configuration, the number of students present, activities and the amount of time spent on them, handouts and props, taping and acoustic problems, and any other problems or comments that were pertinent to that particular class observation. These additional comments that were sometimes noted, pertained to such aspects as student participation within the classroom or whether student 
question asking was done in the Ll or TL. Though students were not the focus of the investigation, these issues were interesting and maybe even relevant to note for future research. The field notes/observation form is in Appendix D. Strict attention was paid to exactly what time the class began and exactly what time it terminated. This was done for the purpose of data analysis.

on the fifth observation of each class, I administered the student questionnaires and thanked the students for allowing me to conduct the study within their classroom. The instructor of Language $B$ did not allow the questionnaire to be done during class time. Instead, the students were to complete it and turn it in to the foreign language office. The instructor was then to deliver it to me.

Teacher interviews were arranged with each teacher during the last two weeks of the term, after all of the observations had been completed. A copy of the questions to be used in the interview was given to each instructor. I felt this would help to expedite the interview process since many of the instructors were on a limited time frame. Another reason for doing this was that since English was not the native language of four of the instructors, I thought they would feel more at ease knowing what was going to be asked. The interviews were not audiotaped, but 
rather written down so as to allow the teacher an opportunity to reflect on the next question. Each interview lasted between twenty to thirty minutes.

\section{ANALYSIS OF DATA}

The data were analyzed with descriptive statistics, with means calculated for various sets of data. These sets of data included the ratio of the L1 versus the TL use, the purposes for which the LI were used employing the categorization system, and the student questionnaires.

\section{Quantitative Analysis}

Concerning research question 1 ) what the ratio of the L1 to TL was, each class was audiotaped and the data were quantified according to actual time spent on utterances in the $L 1$ versus the TL with the use of a digital timer. Only utterances where the instructors addressed the entire class were calculated. Each new utterance was chosen as a starting point and counted on the digital timer as 0:00.

The results were described with percentages. The formula used to obtain the percentage of the TL used for each class was as follows:

time of TL $\div$ time of TL + time of $\mathrm{Ll} \times 100=\%$ of TL The formula used to obtain the percentage of the $\mathrm{Ll}$ used for each class was as follows:

time of $\mathrm{L} 1 \div$ time of $\mathrm{Ll}+$ time of $\mathrm{TL} \times 100=\%$ of $\mathrm{LI}$ 
The ratio was calculated for each individual class and also the percentages were added together to get a final mean of the ratio for all five observations. The percentages were rounded to the tenth of a decimal. The differences between the languages were then compared. Finally, a sample of three of the tapes were analyzed by a second rater to check for inter-rater reliability. over 92\% concordance was achieved. Regarding research question 2) The purposes for which the LI was used, I transcribed selective verbatim, ie. all of the LI utterances. The appropriate category within the categorization grid was marked for each time it occurred and the amount of time spent on each utterance within that particular category was recorded. The results were then calculated to determine the percentage of time spent on each category, if any, in relation to the percentage of total L1 time. The equation used to figure this percentage was:

time in category $x \div$ total Ll time $x 100=\%$ of category $x$ Three of the categorization grids were reviewed by another rater and had an inter-rater reliability score of $93 \%$.

Results of the student questionnaires were compiled using descriptive statistics. The mean of each question was calculated and recorded. Each class was analyzed separately and the differences were compared. 
Analysis of Teacher Interviews

Since the teacher interviews could not be analyzed using descriptive statistics due to the nature of the questions, profiles of the six teachers were given. Any information with respect to $\mathrm{TL}$ and $\mathrm{Ll}$ usage was noted and any other information that proved relevant to the research was noted.

The results of the research methodology specified above are comprehensively discussed in the next chapter. A discussion of the results is covered in chapter $V$ in addition to the limitations of the research methods used in this study. 


\section{CHAPTER IV}

\section{RESULTS OF THE STUDY}

In this chapter, results of the findings for each class are discussed. First, the ratios of the LI to TL are reported for each individual class, as well as the final averages. Next, the purposes for which the $\mathrm{LI}$ is used are discussed, both individually and as class averages. Finally, the results from the student questionnaires are tabulated for each class. Also included in this section are excerpts from teacher interviews when deemed relevant to the investigation.

\section{TO TL USE RESULTS}

The first research question of this investigation was: 1) If II (English) is used in university-level foreign language classrooms, what is the ratio of Ll to TL? It was found that no foreign language class was without the use of the L1. All of the classes utilized the Ll to some degree. Three out of the six classes used the Il an average of $10 \%$ or less. The other three classes, on average used the II $13 \%$ or more of the time. Table I presents the final mean percentage of both the TL and Ll use for each language to make an assessment for overall use. Table II shows the 
percentage of the TL use for each language. Finally, the findings for the percentage of L1 use are reported in Table III for each class. These tables illustrate the the range of LI and TL use more clearly and allow comparisons to be made about the differences across classes.

\section{TABLE I}

MEAN PERCENTAGE OF L1 AND TL USE BY LANGUAGE

TL mean $\quad$ L1 mean

\begin{tabular}{|c|c|c|}
\hline LANGUAGE A & 86.1 & 13.9 \\
\hline & & \\
\hline LANGUAGE B & 73.5 & 26.5 \\
\hline & & \\
\hline LANGUAGE C & 94.3 & 5.7 \\
\hline & & \\
\hline LANGUAGE D & 93 & 7 \\
\hline & & \\
\hline LANGUAGE E & 74.9 & 25.1 \\
\hline & & \\
\hline LANGUAGE F & 92 & 8 \\
\hline
\end{tabular}


TABLE II

PERCENTAGE OF TL USE BY LANGUAGE OVER FIVE CLASSROOM OBSERVATIONS

class 1
\begin{tabular}{|c|c|c|c|c|c|}
\hline LANGUAGE A & 86.1 & 94.4 & 75 & 91.9 & 83 \\
\hline & & & & & \\
\hline LANGUAGE B & 78.9 & 69.7 & 68.9 & 65.8 & 85.7 \\
\hline & & & & & \\
\hline LANGUAGE C & 96.5 & 94.5 & 95 & 94.7 & 90.6 \\
\hline & & & & & \\
\hline LANGUAGE D & 85.4 & 86.4 & 94.9 & 98.6 & 99.9 \\
\hline & & & & & \\
\hline LANGUAGE E & 65.2 & 94.6 & 82.9 & 65.5 & 66.2 \\
\hline & & & & & \\
\hline LANGUAGE F & 97.3 & 87.4 & 93.6 & 94.7 & 86.9 \\
\hline
\end{tabular}

TABLE III

PERCENTAGE OF L1 USE BY LANGUAGE OVER FIVE CLASSROOM OBSERVATIONS

\begin{tabular}{|c|c|c|c|c|c|}
\hline & class 1 & class 2 & class 3 & class 4 & class 5 \\
\hline LANGUAGEA & 13.9 & 5.6 & 25 & 8.1 & 17 \\
\hline LANGUAGE B & 21.1 & 30.3 & 31.1 & 34.2 & 14.3 \\
\hline & & & & & \\
\hline LANGUAGE C & 3.5 & 5.5 & 5 & 5.3 & 9.4 \\
\hline LANGUAGE D & 14.6 & 13.6 & 5.1 & 1.4 & .1 \\
\hline & & & & & \\
\hline LANGUAGE E & 34.8 & 5.4 & 17.1 & 34.5 & 33.8 \\
\hline LANGUAGE F & 2.7 & $\overline{12.6}$ & 6.4 & 5.3 & 13.1 \\
\hline
\end{tabular}

From the preceding tables, it is apparent that the instructor of Language $C$ used the highest degree of TL in the foreign language classroom with a mean percentage of 
94.3. On the otherhand, Language $B$ had the lowest mean percentage of TL use at 73.5 .

Looking though individually at the TL and L1 usage of each particular language, Tables II and III show the breakdown from class 1 through class 5 to get a clearer picture of what transpired within each foreign language classroom. One would expect that the earlier classes would show higher uses of the LI since they are the beginning classes of the term, yet only one class displays this behavior--Language $\mathrm{D}$ which consistently tapers off the use of LI and steadily increases the amount of TL input. Language $B$ and Language $E$ both remained relatively low in TL use throughout the observations, with a high degree of fluctuation between percentages. For example, the instructor for Language $E$ used $65.2 \%$ TL during class 1 . on class 2 , she increased the TL input to $94.6 \%$. On class 3, she dropped a little to $82.9 \%$ TL use, and then steadily decreased the TL use for both class 4 and 5 to the 60th percentile. Language $\mathrm{B}$ also illustrates similar behavior. The instructor starts out with a higher percentage use of the TL during the first class. She utilizes less TL during the next 3 classes, staying within the 60 th percentile. Finally, on the last class the TL use jumps up to $85.7 \%$.

Languages $C, D$, and $F$ all displayed very high degrees 
of TL use throughout the five classes observed. Language A also remained relatively consistent with providing a language rich environment. With Languages B and E though, it seemed more the exception than the norm that the students were being exposed to high quantities of TL input because on an average $25 \%$ LI use was being used by the instructors.

\section{PURPOSES FOR LI USE RESULTS}

The second research question being investigated was: 2) For what purposes is the Il used?

Nine categories were drawn up and marked within the categorization grid for each time that they occurred. The results indicate that four out of the six languages had the highest percentage of Ll talk for language analysis and vocabulary translation. The other two classes also had the highest percentage for language analysis, but differ in that Language A had highest percentages of Ll use for assessment and comprehension checks, whereas Language $B$ had highest percentages of LI use for instructions and prompts. The results for each language, represented by percentages, are as follows listed in the tables below. Each table is followed by a brief description of what has transpired. 
TABLE IV

MEAN PERCENTAGES OF LI OCCURRENCES

\begin{tabular}{|l|l|l|l|l|l|l|}
\hline CATEGORY & A & B & C & D & E & F \\
\hline 1) negotiation of lesson/syllabus & 17.6 & 7 & 7.8 & 13.4 & 12.2 & 9.8 \\
\hline 2) classroom management & & & & & & \\
\hline & 3.8 & 3.4 & - & .6 & .2 & .2 \\
\hline 3) lang analysis/rules & & & & & & \\
\hline & 30.4 & 15.2 & 21.4 & 25 & 30.8 & 21.4 \\
\hline 4) instructions or prompts & & & & & & \\
\hline & 3.6 & 31.4 & 20 & 13 & 3.4 & 2.4 \\
\hline 5) explanations of errors & & & & & & \\
\hline & 5 & 7.2 & 9.6 & 2.6 & 11 & 3.8 \\
\hline 6) assessment/comp checks & 21.4 & 15 & 2.4 & 9.4 & 8.2 & 13.8 \\
\hline & & & & & & \\
\hline 7) maintaining social relations & .4 & 4.6 & - & .4 & 1 & .6 \\
\hline & & & & & & \\
\hline 8) vocabulary translation & 14.2 & 9.6 & 34.8 & 30 & 32.4 & 41.6 \\
\hline & & & & & & \\
\hline 9) other & 3.6 & 6.6 & 4 & 5.6 & .8 & 6.4 \\
\hline
\end{tabular}

This table, Table IV, represents the total averages

for each language in regard to purposes for which the II is used. The results indicate that four out of the six languages have the highest percentage of Ll talk for language analysis and vocabulary translation. These are languages $C$ through $F$. Language $A$, on the other hand while also having the highest percentage for language analysis, had the second highest LI use for assessment and comprehension checks. Language B, had the highest degrees of LI use for both language analysis and instructions or prompts. The LI use most infrequently utilized by the instructors was for purposes of maintaining social 
relations for all of the languages. Il use was also very low for purposes of classroom management.

\section{TABLE V}

PERCENTAGES OF L1 OCCURRENCES FOR LANGUAGE A

$\begin{array}{lllllll}\text { CATEGORY } & \text { CLASS : } & 1 & 2 & 3 & 4 & 5\end{array}$

\begin{tabular}{|l|l|l|l|l|l|}
\hline 1) negotiation of lesson/syllabus & 10 & - & 73 & 5 & - \\
\hline 2) classroom management & & & & & \\
\hline & 13 & 2 & 1 & 3 & - \\
\hline 3) lang analysis/rules & & & & & \\
\hline & 21 & 61 & 1 & - & 69 \\
\hline 4) instructions or prompts & & & & & \\
\hline & 7 & - & 8 & - & 3 \\
\hline 5) explanations of errors & & & & & \\
\hline & 11 & - & 7 & 5 & 2 \\
\hline 6) assessment/comp checks & & & & & \\
\hline & 24 & 4 & 1 & 66 & 12 \\
\hline 7) maintaining social relations & - & - & - & - & 2 \\
\hline & & & & & \\
\hline 8) vocabulary translation & 12 & 24 & 8 & 17 & 10 \\
\hline & & & & & \\
\hline 9) other & 2 & 9 & 1 & 4 & 2 \\
\hline
\end{tabular}

The results from Table $V$, class 1 , show that the instructor for Language A used the Ll for a variety of functions. The highest use, at $24 \%$ was the use of L1 for assessment and comprehension checks. This was closely followed by using English for language analysis and presentation of rules at $21 \%$. The remaining categories differed in percentage use on a point to point basis. The lowest use of the LI was in the 'other' category at $2 \%$. The instructor did not use the Il for maintaining social 
relations.

During class 2, a large portion of the Ll talk was used for language analysis at $61 \%$, followed by vocabulary translation at $24 \%$. Ll use was kept to a minimum for the other categories, while using no Ll at all for negotiation, instructions, explanations of errors, or maintaining social relations.

Class 3 shows that the L1 use is present throughout all of the categories, except maintaining social relations. At $73 \%$ L1 use, the instructor spends the most time on negotiation of the lesson and syllabus. The remaining categories are $8 \%$ or less Ll use, with four categories being used only $1 \%$ of the time in the $\mathrm{Ll}$.

Assessment and comprehension checks are done in the L1 $66 \%$ of the time during class 4 , followed by $17 \%$ for vocabulary translation. The Ll is not used for language analysis, instructions, or maintaining social relations during this class. The rest of the categories are used infrequently at $5 \%$ or less.

Class 5 indicates the highest use of the L1 for language analysis at $69 \%$, the most for all five classes. Assessment and comprehension checks are used $12 \%$ of the time, followed by vocabulary translations at $10 \%$. For the first time, the instructor uses the Ll for maintaining social relations at a low $2 \%$. The $\mathrm{Ll}$ is not used for 
negotiation of the lesson or syllabus or for classroom management during this lesson.

TABLE VI

PERCENTAGES OF LI OCCURRENCES FOR LANGUAGE B $\begin{array}{lllllll}\text { CATEGORY } & \text { CLASS : } & 1 & 2 & 3 & 4 & 5\end{array}$

\begin{tabular}{|l|l|l|l|l|l|}
\hline 1) negotiation of lesson/syllabus & 7 & 6 & 11 & 5 & 6 \\
\hline 2) classroom management & & & & & \\
\hline & - & 7 & 8 & - & 2 \\
\hline 3) lang analysis/rules & & & & & \\
\hline & 14 & 12 & 32 & 7 & 11 \\
\hline 4) instructions or prompts & 28 & 33 & 20 & 53 & 23 \\
\hline & & & & & \\
\hline 5) explanations of errors & 7 & 12 & 8 & 8 & 1 \\
\hline & & & & & \\
\hline 6) assessment/comp checks & 18 & 16 & 14 & 6 & 21 \\
\hline & & & & & \\
\hline 7) maintaining social relations & 3 & 7 & 1 & 12 & - \\
\hline & & & & & \\
\hline 8) vocabulary translation & 9 & 5 & 4 & 7 & 23 \\
\hline & & & & & \\
\hline 9) other & 14 & 2 & 2 & 2 & 13 \\
\hline
\end{tabular}

\section{LANGUAGE B}

Table VI, representing Language $B$ indicates that during class 1 , Ll use was highest for instructions or prompts at $28 \%$. This is followed by $18 \%$ LI use for assessment and comprehension checks. Both categories, 'language analysis' and 'other' tie at 14\% L1 use. The remaining categories have quite low percentages of L1 use, with none for classroom management.

Class 2 shows that again the instructor used the highest degree of L1 use for instructions or prompts at 
$33 \%$ And as with class 1, assessment and comprehension checks was the next most frequently used category for the Il at $16 \%$. All of the other purposes for which the II was used, were utilized to some degree $12 \%$ or less of the time. In class 3 , the instructor used the LI mostly for language analysis, instructions, and assessment or comprehension checks. All of the other categories show lower degrees of Ll use. At 53\% Ll use for instructions or prompts, class 4 indicates the highest use of English in this category. This is followed by $12 \%$ LI use for maintaining social relations. No Ll is used for classroom management. The remaining categories indicate $8 \%$ or less LI use. Class 5 shows the highest use of Ll tying at $23 \%$ for both instructions and vocabulary translation. Assessment and comprehension checks trail closely at 21\% LI use. No Ll is used for maintaining social relations, compared to the previous classes. 
TABLE VII

PERCENTAGES OF LI OCCURRENCES FOR LANGUAGE C

$\begin{array}{llllllll}\text { CATEGORY } & \text { CLASS : } & 1 & 2 & 3 & 4 & 5\end{array}$

\begin{tabular}{|l|l|l|l|l|l|}
\hline 1) negotiation of lesson/syllabus & - & - & - & 39 & - \\
\hline 2) classroom management & - & - & - & - & - \\
\hline & & & & & \\
\hline 3) lang analysis/rules & - & 34 & - & 33 & 40 \\
\hline & & & & & \\
\hline 4) instructions or prompts & - & 9 & 84 & 5 & 2 \\
\hline & & & & & \\
\hline 5) explanations of errors & - & 3 & - & - & 45 \\
\hline & & & & & \\
\hline 6) assessment/comp checks & - & 6 & - & 5 & 1 \\
\hline & & & & & \\
\hline 7) maintaining social relations & - & - & - & - & - \\
\hline & & & & & \\
\hline 8) vocabulary translation & 100 & 30 & 16 & 18 & 10 \\
\hline & & & & & \\
\hline 9) other & - & 18 & - & - & 2 \\
\hline
\end{tabular}

LANGUAGE C

The results from Table VII, which pertain to Language $C$ indicate that in class 1 , the instructor only used the Ll for vocabulary translation.

Class 2 shows that the instructor utilized the LI mostly for language analysis at $34 \%$. Vocabulary translation at $30 \%$ closely follow. No LI is used for negotiation of lesson, classroom management, or for maintaining social relations.

The purposes for which the Ll is used during class 3 indicate the instructor only spent utterances on instructions or prompts at $84 \%$ and vocabulary translation 
at $16 \%$.

Class 4 shows the highest use of the LI for negotiation of the lesson or syllabus at $39 \%$, followed closely by $33 \%$ for language analysis. The instructor did use the L1 for vocabulary translation at $18 \%$ and tied at 5\% for both instructions or prompts and assessment and comprehension checks.

$45 \%$ of L1 utterances were for explanations of errors during class 5. A majority of the time was spent on language analysis at $40 \%$. No Ll was used for negotiation of the lesson, or for classroom management and maintaining social relations. The latter two categories were never used by the instructor.

\section{TABLE VIII}

PERCENTAGES OF LI OCCURRENCES FOR LANGUAGE D

CATEGORY CLASS : 1
\begin{tabular}{|l|l|l|l|l|l|}
\hline 1) negotiation of lesson/syllabus & 30 & 37 & - & - & - \\
\hline & & & & & \\
\hline 2) classroom management & - & 3 & - & - & - \\
\hline & & & & & \\
\hline 3) lang analysis/rules & - & 16 & 56 & 53 & - \\
\hline & & & & & \\
\hline 4) instructions or prompts & 27 & 9 & 17 & 12 & - \\
\hline & & & & & \\
\hline 5) explanations of errors & - & 13 & - & - & - \\
\hline & & & & & \\
\hline 6) assessment/comp checks & 10 & 12 & 25 & - & - \\
\hline & & & & & \\
\hline 7) maintaining social relations & 2 & - & - & - & - \\
\hline & & & & & \\
\hline 8) vocabulary translation & 3 & 10 & 2 & 35 & 100 \\
\hline & & & & & \\
\hline 9) other & 28 & - & - & - & - \\
\hline
\end{tabular}




\section{LANGUAGE D}

Table VIII representing Language D indicates high degrees of Il use for negotiation of lesson or syllabus, other, and instructions or prompts at $30 \%, 28 \%$, and $27 \%$ respectively. The other categories were used minimally or not at all.

Class 2 shows that the instructor used the most LI for negotiating the lesson or syllabus at $37 \%$. The Ll was also used frequently for language analysis at $16 \%$, explanations of errors at $13 \%$, and assessment and comprehension checks at $12 \%$. No L1 was used for maintaining social relations or for other reasons. A large portion of the Ll utterances during class 3 was spent on language analysis at $56 \%$. This is followed by $25 \%$ L1 use for assessment and comprehension checks. Instructions or prompts were used $17 \%$ of the time, while only $2 \%$ of L1 utterances were for the purpose of vocabulary translation.

For class 4 the instructor only used the Ll for language analysis at 53\%, vocabulary translation at $35 \%$, and instructions or prompts at $12 \%$.

All L1 utterances during class 5 were spent on vocabulary translation, the most time spent during all five classes. 
TABLE IX

PERCENTAGES OF LI OCCURRENCES FOR LANGUAGE E

$\begin{array}{lllllll}\text { CATEGORY } & \text { CLASS : } & 1 & 2 & 3 & 4 & 5\end{array}$

\begin{tabular}{|l|l|l|l|l|l|}
\hline 1) negotiation of lesson/syllabus & 34 & 7 & - & 3 & 17 \\
\hline & & & & & \\
\hline 2) classroom management & 1 & - & - & - & - \\
\hline & & & & & \\
\hline 3) lang analysis/rules & 40 & - & 18 & 61 & 35 \\
\hline & & & & & \\
\hline 4) instructions or prompts & 3 & - & - & 9 & 5 \\
\hline & & & & & \\
\hline 5) explanations of errors & 16 & - & 3 & 13 & 23 \\
\hline & & & & & \\
\hline 6) assessment/comp checks & 3 & 10 & 10 & 6 & 12 \\
\hline & & & & & \\
\hline 7) maintaining social relations & - & - & 3 & 1 & 1 \\
\hline & & & & & \\
\hline 8) vocabulary translation & 2 & 83 & 66 & 6 & 5 \\
\hline & & & & & \\
\hline 9) other & 1 & - & - & 1 & 2 \\
\hline
\end{tabular}

\section{LANGUAGE E}

Table IX shows the results for Language E. Class 1 indicates the most Il use for language analysis at $40 \%$ and negotiation of lesson or syllabus at $34 \%$. Some time is also spent on explanations of errors at $16 \%$. The rest of the categories show minimal use of the II with no LI use for maintaining social relations.

\section{During class $2,83 \%$ of L1 utterances are for} vocabulary translation. The only other categories used are assessment and comprehension checks at $10 \%$ and negotiation of the lesson or syllabus at $7 \%$. 
Class 3 once again shows high usage of the L1 for vocabulary translation at $66 \%$. This is followed by $18 \%$ LI use for language analysis. No $L I$ is used for negotiation of the lesson, classroom management, instructions or promts, or for other purposes.

$61 \%$ of all Ll utterances are used for language analysis during class 4 . This is followed by $13 \%$ LI use for explanation of errors. The instructor spent $9 \%$ or less on other reasons for using the L1. No time was spent on classroom management.

Class 5 indicates the highest use of the LI for language analysis at $35 \%$ Explanations of errors at $23 \%$ L1 use and negotiation of the lesson or syllabus at $17 \%$ L1 follow. Minimal uses for the Ll are evident within the remaining categories as well as no $\mathrm{Ll}$ use for classroom management. 
TABLE $X$

PERCENTAGES OF LI OCCURRENCES FOR LANGUAGE $F$

$\begin{array}{lllllll}\text { CATEGORY } & \text { CLASS : } & 1 & 2 & 3 & 4 & 5\end{array}$

\begin{tabular}{|l|l|l|l|l|l|}
\hline 1) negotiation of lesson/syllabus & 36 & 13 & - & - & - \\
\hline & & & & & \\
\hline 2) classroom management & - & 1 & - & - & - \\
\hline & & & & & \\
\hline 3) lang analysis/rules & - & 19 & - & 18 & 70 \\
\hline & & & & & \\
\hline 4) instructions or prompts & 2 & 1 & - & 9 & - \\
\hline & & & & & \\
\hline 5) explanations of errors & - & 2 & - & 17 & - \\
\hline & & & & & \\
\hline 6) assessment/comp checks & 13 & 16 & - & 31 & 9 \\
\hline & & & & & \\
\hline 7) maintaining social relations & - & 2 & - & - & 1 \\
\hline & & & & & \\
\hline 8) vocabulary translation & 44 & 27 & 96 & 22 & 19 \\
\hline & & & & & \\
\hline 9) other & 5 & 19 & 4 & 3 & 1 \\
\hline
\end{tabular}

\section{LANGUAGE $F$}

Table $X$ depicts the results for Language $F$. Class 1 shows the most LI use for vocabulary translation at $44 \%$ and negotiation of the lesson or syllabus at $36 \%$. The remaining categories show low or no L1 use.

Class 2 indicates the instructor used the most L1 for vocabulary translation at $27 \%$. Other categories show close percentages of LI use for other purposes at $19 \%$, language analysis at $19 \%$, assessment and comprehension checks at $16 \%$ and negotiation of the lesson or syllabus at $13 \%$. The rest of the categories show $2 \%$ or less LI use.

Ll was utilized only for vocabulary translation at $96 \%$ 
and for other purposes at $4 \%$ during class 3.

Class 4 indicates that the highest use of L1 occurred for assessment and comprehension checks at $31 \%$. Following somewhat closely is $22 \%$ L1 use for vocabulary translation, 18\% Il use for language analysis, and $17 \%$ Il use for explanations of errors. The remaining categories show infrequent or no LI use.

The highest use for LI by the instructor was at $70 \%$ for language analysis during class 5. This is followed by 19\% LI use for vocabulary translations. Only $9 \%$ L1 was used for assessment and comprehension checks. Both maintaining social relations and other purposes tie at $1 \%$ L1 use.

\section{STUDENT QUESTIONNAIRE RESULTS}

The results from the student questionnaire address the third research question of this investigation which deals with the attitudes and perceptions of the students in regard to instructor L1 use within the foreign language classroom. The results have been tallied and presented in the following tables, followed by a description of what transpired. Table XI addresses the first question on the student questionnaire which deals with the students' exposure to the foreign language. More than one category could be checked so the numbers do not add up to $100 \%$. 
The $\mathbf{n}$ in the following tables stands for the number of students who completed questionnaires. The number before each parentheses signifies the number of students who checked that particular response.

\section{TABLE XI}

\section{STUDENTS' EXPOSURE TO FOREIGN LANGUAGE}

(Question \#2 on the student Questionnaire: Where have you had exposure to this foreign language? Please check all that are relevant)

$\mathbf{n}=$ number of students who completed questionnaires

$A=$ at home or elsewhere in the local community

$B=$ in the country where language is spoken

$\mathrm{C}=$ previous courses before this academic year

$D=$ no other experience other than the first year course

$\begin{array}{lllll}\mathbf{n} & \mathbf{A} & \mathbf{B} & \mathbf{C} & \text { D }\end{array}$

\begin{tabular}{|c|c|c|c|c|c|}
\hline LANGUAGE A & 10 & $2(20 \%)$ & $6(60 \%)$ & $6(60 \%)$ & $2(20 \%)$ \\
\hline & & & & & \\
\hline LANGUAGE B & 3 & $2(67.7 \%)$ & $2(66.7 \%)$ & $3(100 \%)$ & $0(0 \%)$ \\
\hline & & & & & \\
\hline LANGUAGE C & 12 & $2(16.6 \%)$ & $7(58.3 \%)$ & $9(75 \%)$ & $1(8 \%)$ \\
\hline & & & & & \\
\hline LANGUAGE D & 13 & $6(46.2 \%)$ & $8(61.5 \%)$ & $9(69.2 \%)$ & $0(0 \%)$ \\
\hline LANGUAGE E & 13 & $5(38.5 \%)$ & $5(38.5 \%)$ & $10(76.9 \%)$ & $3(23 \%)$ \\
\hline & & & & & $9(77.3 \%)$ \\
\hline LANGUAGE F & 22 & $12(54.5 \%)$ & $9(41 \%)$ & $17 \%)$ \\
\hline
\end{tabular}

Results of Table XI

The purpose of the first question on the student questionnaire was to get an idea of where the students have 
had exposure to the TL. Though the question is general in that it does not address how much exposure they have had or the quality of the exposure, it does give a sense of the nature of the exposure. In only two of the classes, over half of the students stated having had exposure to the TL at home or elsewhere in the local community. In four of the classes, over half of the students have had exposure in the country where the language is spoken. Over three quarters of the students in almost all of the classes reported having had exposure to the TL in previous courses. And finally, only very few students have had no experience other than the first quarter class.

\section{TABLE XII}

STUDENTS' REPORT OF INSTRUCTORS' L1 USAGE

(Question \#3 on the Student Questionnaire: How much English does your teacher typically use in class?)

\begin{tabular}{|c|c|c|c|c|c|}
\hline & $\mathbf{n}$ & "A Lot" & "Some" & "Very Little" & "Never" \\
\hline LANGUAGE A & 10 & $0(0 \%)$ & $1(10 \%)$ & $9(90 \%)$ & $0(0 \%)$ \\
\hline LANGUAGE B & 3 & $0(0 \%)$ & $1(33.3 \%)$ & $2(66.7 \%)$ & $0(0 \%)$ \\
\hline LANGUAGE C & 12 & $2(16.7 \%)$ & $0(0 \%)$ & $9(75 \%)$ & $1(8.3 \%)$ \\
\hline LANGUAGE D & 13 & $1(7.7 \%)$ & $3(23.1 \%)$ & $9(69.2 \%)$ & $0(0 \%)$ \\
\hline LANGUAGE E & 13 & $3(23 \%)$ & $8(61.6 \%)$ & $2(15.4 \%)$ & $0(0 \%)$ \\
\hline LANGUAGE F & 22 & $4(18.2 \%)$ & $11(50 \%)$ & $7(31.8 \%)$ & $0(0 \%)$ \\
\hline
\end{tabular}


Results of Table XII

Table XII displays the results to the question asking students to "report" on the amount of LI used by the instructor. In four of the classes, a quarter or less of the students checked that the instructor used "a lot" of English and in the other two classes, no one reported the instructor used "a lot" of the Ll. Only in two classes, did over half of the students feel the teacher used "some" English. For the remaining four classes only a few students reported that. In four of the classes, over half of the students reported that the instructor used "very little" Ll in class. Finally, only one student reported that the L1 was "never" used by the instructor. 
STUDENTS' DESIRED ATTITUDES TOWARD DESIRED ENGLISH USAGE BY INSTRUCTOR

(Question \#4 on the student Questionnaire: How much English would you like your teacher to use in class?)

$\mathbf{n}=$ number of students who completed questionnaires
$A=$ more English than now
$B=$ the same amount as now
$c=$ less English than now

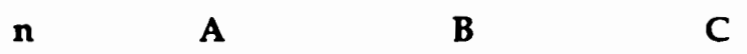

\begin{tabular}{|c|c|c|c|c|}
\hline LANGUAGE A & 10 & $2(20 \%)$ & $8(80 \%)$ & $0(0 \%)$ \\
\hline & & & & \\
\hline LANGUAGE B & 3 & $1(33.3 \%)$ & $2(66.7 \%)$ & $0(0 \%)$ \\
\hline & & & & \\
\hline LANGUAGE C & 12 & $2(16.7 \%)$ & $9(75 \%)$ & $1(8.3 \%)$ \\
\hline LANGUAGE D & 13 & $3(23.1 \%)$ & $8(61.5 \%)$ & $2(15.4 \%)$ \\
\hline & & & & $3(23 \%)$ \\
\hline LANGUAGE E & 13 & $1(8 \%)$ & $9(69 \%)$ & \\
\hline & & & & $4(18.2 \%)$ \\
\hline LANGUAGE F & 22 & $0(0 \%)$ & $18(81.8 \%)$ & \\
\hline
\end{tabular}

Results of Table XIII

Table XIII shows the amount of the Ll the students would like the instructor to use. In all of the classes, except one, one-third or less of the students reported wanting "more English than now" in their foreign language classes. In all of the classes, more than half of the students wanted "the same amount of English as now". And finally, in four of the classes one-quarter or less of the 
students reported wanting "less English than now".

TABLE XIV

STUDENTS' PERCEPTION OF COMPREHENDED

INSTRUCTOR TL TALK

(Question \#5 on student Questionnaire: How much of your teacher's foreign language do you understand in class?)

$\mathbf{n}=$ number of students who completed questionnaires
$A=$ understand all
$B=$ understand most of it
$c=$ understand some of it
$D=$ understand very little

$\begin{array}{lllll}\mathbf{n} & \mathbf{A} & \mathbf{B} & \mathbf{C} & \mathbf{D}\end{array}$

\begin{tabular}{|c|c|c|c|c|c|}
\hline LANGUAGE A & 10 & $1(10 \%)$ & $8(80 \%)$ & $0(0 \%)$ & $1(10 \%)$ \\
\hline LANGUAGE B & 3 & $2(66.7 \%)$ & $0(0 \%)$ & $1(33.3 \%)$ & $0(0 \%)$ \\
\hline LANGUAGEC & 12 & $2(16.7 \%)$ & $6(50 \%)$ & $4(33.3 \%)$ & $0(0 \%)$ \\
\hline LANGUAGE D & 13 & $3(23.1 \%)$ & $9(69.2 \%)$ & $1(7.7 \%)$ & $0(0 \%)$ \\
\hline LANGUAGE E & 13 & $4(30 \%)$ & $8(62 \%)$ & $1(8 \%)$ & $0(0 \%)$ \\
\hline LANGUAGE F & 22 & $4(18.2 \%)$ & $15(68.2 \%)$ & $3(13.6 \%)$ & $0(0 \%)$ \\
\hline
\end{tabular}

Results of Table XIV

The last question of the student questionnaire asked how much of the instructors' foreign language does the student understand. In four of the classes, one-quarter or less of the students "understand all". Only in one class did over half of the students report to "understanding al1". In five of the classes, almost two-thirds or more 
of the students reported to "understanding most of it". In five of the classes one-third or less of the students felt they "understood some of it". And in only one of the classes did one student report "understanding very little".

\section{TEACHER INTERVIEW RESULTS}

Each of the six teachers will be briefly profiled below to give a general description of their teaching history and experience. Additional notes will be added when considered relevant. More attention will be paid to the Teacher Interviews in the following chapter.

\section{Language A Teacher}

This instructor has taught three terms at Portland State University. Prior to this, she taught pre-school immersion classes. Her background is in language teaching, Iinguistics, and literature, though her Master's degree specifically emphasizes foreign language and literature. She has no problems with Language $A$ because she is a native speaker and prefers to speak that in the classroom. She also is fluent in English, having resided in the United States for several years.

She said when she does use the LI, it is usually for administrative issues, grammar analysis, or upon student demand. She emphasized that the use of English should be 
very minimal and used only for necessary things, with the TL being utilized about $90 \%$ of the time. Her belief that the best way to learn a language is to be immersed within that country. In regard to instruction, she recognizes the importance of the Proficiency movement, but also believes that grammar analysis is important for some students.

\section{Language $B$ Teacher}

This instructor has only been in the United States for a short period. Her experience includes having taught two terms at Portland State University. She currently holds a $B A$ in English and Economics from her native country. She is enrolled here in the United States for her Masters in language and literature. Her pronunciation of the LI may be a bit of a problem for the students, but she reports to being almost fluent in English. She said she tries to use the $\mathrm{Ll}$ as little as possible, but sometimes relies on it to clarify grammar points, for vocabulary translation, or if the students seem confused. She said it depends on the class, but she believes that the TI should be used $90 \%$ of the time. Her approach to teaching language $B$ is to concentrate on the four areas, but the main goal of language should be communication. Because she has not been teaching very long, she admitted to being unsure of the best way to teach a language. 


\section{Language Teacher C}

This instructor has been certified to teach language $C$ for kindergarten through twelth grade. He also has had seven years total teaching university level language and literature courses. currently he is working towards a Master's degree. His main concentration has been primarily on literature and language acquisition theory. He reported to being very fluent in Language $c$, though it is not his native language. He said he rarely speaks the Ll in class, and if he does it is only for the purposes of grammar analysis or vocabulary translation. Throughout the interview he often referred to the Proficiency movement and mentioned the ACTFL scoring system in reference to his and students language ability.

His thoughts on the best way to learn a language is to study in the country of the TL. The best way to learn here is to study in a classroom environment which simulates the target environment. He believes strongly that next to no Ll should be utilized within the classroom because it is not necessary.

\section{Language Teacher D}

This instructor is the only one who was not a teaching assistant, instead she has been hired as a language instructor. She has had five years total teaching Language D. Two of those years were at the community college and 
the last three have been at Porland state University. Her undergraduate degree was in the foreign languages in her native country. Here in the United States she is working towards her Master's degree in Iinguistics.

She reported to using the $\mathrm{Ll}$ for informal discussions and explanations, but otherwise is more comfortable using the TL because she does not make mistakes in her Ianguage. She does not want to confuse the students. She said she specifically uses the Il for homework explanations upon the students request and to clarify idiomatic forms or jokes.

Her belief is that the best way to learn a language is to be pro-active. This means doing activities which will put students in touch with the TL. This could include going to the cinema to see foreign films, reading magazines that are written in the TL, and having conversations with TI speakers. She believes the best way to teach a language is to provide less structured instruction. She wants to provide interesting material that is also practical. Her main emphasis is on the speaking skills, though writing is sometimes stressed too.

She believes that the Il should not be used in the classroom although it is acceptable to use it outside of the class. Ideally, she would like to not use the II at all because it limits the input students receive. Also switching back and forth can be confusing. 
Language Teacher $\mathrm{E}$

This instructor's teaching experience includes having taught conversation to adults at the community college level for three years, one month in a private school to tenth through twelth graders, and two years at Portland State University. Her background is in Iiterature and language teaching, which is also what she is getting her Master's Degree in. She feels very proficient in Language E, though it is not her native language. She has spent over two years in the TL countries. English is also not her native language, but she is fluent, having spent a few years in the United states.

She said she tries to use the Ll as little as possible, usually for grammatical or confusing points. Although she does admit to using the TL first, she sometimes will resort to the II if the students seem confused. She does not agree with instructors who use only the TL, because she realizes the anxiety it causes for some students. She believes the best way to learn a language is to live in the TL country and immerse oneself in it. In the classroom she stated that she tries to emphasize all areas. She also feels that grammar needs to be learned instead of mechanically memorized. The students need to learn the application. 


\section{Language Teacher $\mathrm{F}$}

This instructor has had eight years experience teaching Language $F$ to a variety of populations. He currently teaches at the high school level, at the community college level, and at the university level. Two of those classes, at the community college, are for native speakers because they do not have a strong basis in their own language. He helps with literacy, grammar knowledge, and writing composition. His background is in language teaching, linguistics, and literature. Currently he is working towards a Master's degree in language and literature.

Though Language $F$ is not his native language, he feels he is quite fluent since he has spent time in TL countries and because he has had exposure to the TL as a child.

He feels that the TI should be used as much as possible, but does not rule out using the LI because he realizes that many students have not had that much exposure to the language. He reported using the LI especially for grammar analysis, testing, and to ease the anxiety of the students.

He does not believe that there is one best way to learn or teach a language. He stated that one must be malleable and ecclectic by trying to incorporate a variety of methods into one's teaching. He stressed that to him, 
the teaching of literature is essential because it offers a cultural, historical, and socio-political view. 
CHAPTER V

\section{DISCUSSION OF THE RESULTS}

This chapter of the investigation discusses in greater detail the results of the findings. First, the ratios of the Ll to TL for the classes observed are discussed, both individually and as a whole. Next, the purposes for which the LI are used are commented upon, to show possible trends that have occurred. Finally, the results from the student questionnaires are further analyzed. Also included is more insight into the teacher interviews to help draw some conclusions about teacher L1 and TL use. The interviews help to clarify what is happening within the classrooms versus the teachers' perception of what is happening.

\section{L1 TO TL USE RESULTS}

The first research question of the investigation was: 1) If Ll (English) is used in university-level foreign language classrooms, what is the ratio of L1 to TL?

It would be unrealistic to expect complete avoidance of L1 use from instructors. As some researchers have agreed, (Auerbach, 1993, Akinson, 1987) the use of the L1 can help to facilitate the lesson by saving time and ensuring comprehension. In addition, it may lower the 
anxiety level of the students. In my observations, I found that the instructors for Languages C, D, and F did not utilize the Ll very often. They used it to aid in comprehension, but usually tried other tricks to not have the students rely on English. It is interesting to note that in the classes where the instructors used the highest degrees of the TL that students seemed more active, participating more regularly than Language $B$ and $E$. In the following section, I will discuss individually what was going on within each classroom in regard to L1 and TL use, as well as commenting on instructor practices and behavior.

\section{Language A}

The instructor for Language A used relatively high degrees of the TL. The classes where the LI input was high (25\% for class observance 3 and $17 \%$ for class observance 5) the instructor was either preparing the students for an upcoming exam or disscussing the results of a previously taken exam. This accounts for the higher degrees of LI use. She spent a great deal of time explaining in detail certain grammatical points and grading techniques upon the request of the students. Throughout my observations of this class, I noticed that the students almost always asked questions in the LI and when they did utilize the TL it was often with some difficulty. On the otherhand, the 
instructor greatly encouraged the TL and would respond in the TL even if addressed in the LI. However, she would revert to the Ll if students seemed confused or if they demanded explanations.

The instructor used a lot of repetition and gestures to convey points in the TL. She also used props effectively to encourage students to speak the TL. Unfortunately, the students often seemed hesitant to talk, and it was normally the same students who did the majority of the speaking. The instructor did not seem to do anything to remedy this. She could have tried involving some of the quieter students by encouraging them to participate and practice the language.

\section{Language $B$}

This instructor used the highest degrees of the $\mathrm{Ll}$ of all the instructors. She used an average of $26 \% \mathrm{Ll}$ use over five observations. Only on the fifth and last observation did she use low amounts of the Ll at $14 \%$. The students often came in late to class, were unprepared for lessons, and repeatedly asked questions in the LI. In addition, no one ever really volunteered to answer questions. Though a native speaker of Language $B$, the instructor spent much time using the LI and often addressed the students individually in the LI. Though she did ask the students on several occasions to utilize the 
TL, she did not often set the example or try to enforce it. Language $c$

The insructor of this class used the highest quantities of TL at $94 \%$. He consecutively used $9 \%$ or less Il use over the five observations. It is interesting to note that he was not a native speaker of Language $C$. This instructor was very interactional and seemed to have a good rapport with the students. He tried to involve all of the students, giving each an opportunity to speak in the TL. It was noted that the students rarely asked questions in the Ll, and also would answer in the TL when the instructor asked grammatical questions.

He sometimes utilized gestures instead of the L1 to convey vocabulary. He often used the blackboard to illustrate points not understood or clear to the students. For the most part he used the TL for grammatical explanations unless the students requested clarification in the $\mathrm{Ll}$.

\section{Language D}

The instructor of this class had high quantities of TL use at an average of $93 \%$ for the five classes observed. Her class was the only one which consistently tapered off the use of the LI and steadily increased the amount of TL input. It was observed that she spoke individually to students in the TL when circulating throughout the class 
during groupwork. She often utilized props to convey the language and certain grammatical stuctures. This was the only class observed where students took part in role play and group demonstrations.

The instructor used minimal amounts of the $L I$ and really made an attempt to conduct explanations in the TL, even when students asked questions in the Ll or expressed confusion. She would try first in the TL and then the LI if needed. She was the only instructor that was not a teaching assistant.

\section{Language $\mathbf{E}$}

This language instructor used high degrees of the LI at an average of $25 \%$. Only during classroom observation two did she use minimal amounts of the Ll at 5\%. This indicates the inconsistency of this instructor's language choice as it was also observed that she regularly alternated between the $\mathrm{Ll}$ and the $\mathrm{TL}$ when teaching the class.

On a couple of occasions she did encourage the students to use the TL but never really implemented that. This instructor did a lot of Ll explanation about upcoming exams, grammar analysis, and for translations. The students often asked questions in the Ll, not even attempting to use the TL. I found it to be odd that the instructor on two occasions had the students take turns 
reading the text which was written in the Ll. The readings would last for at least 10 minutes in a fifty minute classroom session.

\section{Language $\mathrm{F}$}

This instructor used a great degree of TL use at an average of $92 \%$. He was not a native speaker. On the two classroom occasions where he did utilize more Ll (class 2 at $12 \%$ and class 5 at $13 \%$ ) it was to discuss problems with a previously taken exam that was ambiguous to several students, especially concerning grading techniques. When he did conduct grammar explanations about the exam, he first explained in the TL and then reverted to the L1 if students had not grasped it.

The instructor was very interactional with the students, often joking with them. He thoroughly explained points in the TL, especially on the blackboard with drawings. He encouraged the students to use the TL, which they often did, even while doing unsupervised group work. This was the largest class that I oberved, yet the majority of the students seemed to be engaged in the activities, participating often.

\section{PURPOSES FOR LI USE}

The second research question being researched was: 2) For what purposes is the LI used? 
Of course the purposes for LI use varied from lesson to lesson among the classes observed, depending on what the main focus of the particular lesson of the day was. Each individual language will be profiled and discussed below to further analyze for what purposes the LI was used. Language $\mathbf{A}$

The instructor of Language A used the LI mostly for language analysis. This is especially clear on the days where the instructor's LI use is high (class 1 at 25\% and class 5 at $17 \%$ ). On both days the instructor was either preparing the students for an exam or going over a previously taken exam. In either case, the students were grappling with grammar questions. One student in particular voiced a great deal of confusion about a grammatical point which led the instructor to go into an explicit explanation of language analysis. It seemed at times that her explanations were overly lengthy and unnecessary. Although she seemed to have cleared the point, she often would continue on.

What was different about Language $A$ from the other languages was that the instructor used the LI most for purposes of assessment and comprehension checks. This could perhaps suggest that she was aware of her students' unease and confusion regarding language issues. She may have wanted to make sure that everything was clearly 
understood, as she appeared to be concerned about her students' needs. Because she was a native speaker, it may have made the language a bit more difficult for the students to comprehend.

\section{Language B}

This instructor had the highest use of Ll for purposes of instructions and prompts compared to the other five languages, and accordingly had the highest mean LI use. She spent much of the class time explaining to the students what they were responsible for and how to do certain activities. Usually they were simple instructions that easily could have been conducted in the TL. It seemed she wasted unnecessary time telling the students what to do. Interestingly, she was the one instructor that had the highest percentage of LI use for purposes of maintaining social relations. Perhaps this was because she was the youngest of the instructors and also the least experienced. As an observer, it seemed to me that she was concerned that her students like her. Another relevant point is that although she was a native speaker of the language she was teaching, she used the most II of all the instructors.

\section{Language $C$}

The instructor of Language $c$ used the LI the most for purposes of language analysis and vocabulary translation. He also used the least LI of all of the instructors, so the 
amounts that he actually used for these purposes were in fact quite low. He often did language explanations in the TL first. Only if the students asked or if they seemed not to understand would he use the Ll. This is especially illustrated on an occasion when he was reviewing an exam and was covering more complex language rules.

He used the highest degrees of the LI, which was at an average of $5 \%$, for purposes of vocabulary translation. He recognized the need for expediting the lesson by giving the vocabulary in the LI if needed.

\section{Language D}

The instructor of Language $\mathrm{D}$ also used low quantities of the $\mathrm{Ll}$ at an average of $7 \%$. When she did use the L1, it was most often for purposes of language analysis and vocabulary translation. On the classes that I observed, it seemed the instructor tried to use innovative ways to convey the foreign language in the TL without having to revert to the $\mathrm{Ll}$.

once when recounting a comical personal story in the $T L$, the instructor realized the students had not comprehended the gist of the story. This was probably due to the unfamiliar vocabulary and idiomatic expressions. She then retold the story in the Ll so that everyone would understand. In doing this, she taught the unfamiliar vocabulary and expressions. 
Language $\mathrm{E}$

The instructor of Language $E$ used the LI most often for purposes of language analysis and vocabulary translation. She also had the second highest quantities of Ll use at an average of $25 \%$. The classes observed that the LI was the highest, often were on days when the students were reviewing for an exam or discussing an upcoming one. In these cases, the L1 was often used for language analysis. While it was observed that the instructor seemed to give thorough grammar explanations, she often switched back and forth between the TI and the L1. She may not have even been conscious of it. This switching back and forth may have confused the students even more as it dia not set the pattern for TL use.

\section{Language $\mathbf{F}$}

The instructor for this class was among one of the highest for TL use at an average of $92 \%$. He used the LI mainly for purposes of vocabulary translation, followed by language analysis. The amount of time actually spent on these categories was in fact very low in correlation to the average LI percentages. It was observed that his language explanations were usually executed in the TL, yet he would not deny his students $L 1$ explanations if they did not understand. He seemed to be interested in increasing his students acquisition of vocabulary as he encouraged them 
to learn and use new words. To help with this process, if a word was unknown he would use gestures, drawings, or synonyms. If that failed to be understood, the LI was used. He probably utilized the Il the most for purposes of vocabulary translation because the students were encouraged to read pieces of literature which exposed them to new and unfamiliar words.

\section{STUDENT QUESTIONNAIRES}

The purpose of the student questionnaire was to help explore students' perceptions and attitudes regarding use of the Il in the foreign language classroom. Due to the briefness of the questionnaire, it does not specifically delve into student opinion and thought, yet it does allow one to draw several inferences and make some simple generalizations of trends that seemed to be occurring. Instead of going over each individually, I will comment on interesting occurrences. It also must be noted that with Language $B$, the instructor did not permit me to distribute the questionnaire during class time. Instead, the students were to complete it and hand it in to her. She was then to return it to me. Only three of the ten students completed it. I approached her on two occasions, reminding her to encourage the class to complete the questionnaire. I feel she did not take this seriously and may not have even said 
anything to her class. For this reason, the questionnaire results from Language $B$ cannot be considered valid.

For all six languages it is relevant to stress that 'interest' was the number one reason for taking the foreign language class, which was then followed by 'requirement'. This suggests that many of the students chose to be there and maybe had more incentive to learn a foreign language. Also for all six languages in the investigation, the highest percentage of where students have had exposure to the TL was in 'previous courses before the academic year'. This indicates that perhaps the students were taking courses in the foreign language other than just the required classes. It is interesting too that many students indicated having spent time in the country where the language is spoken. Unfortunately, due to the briefness of the questionnaire it is not known for how long or what the nature of the exposure was. Yet it does suggest that students are being exposed or have been exposed to the TL in areas other than the classroom, perhaps being exposed to more authentic input.

In all six languages, $23 \%$ or less of the students had 'no other experience other than the first year course'. These were probably the students expressing confusion during my observations. Since it seems many of the students have already had exposure to the foreign language, 
these particular students who have had no other experience except the first year course may have felt more vulnerable as the other students had had more experience. These may have been the students who indicated they would like their instructor to use more $\mathrm{Ll}$ in class.

One question on the questionnaire asked students to report how much English their teachers typically used in class. This particular question was used to indicate student perception of what was going on in the classroom versus actual II amounts that the teachers were observed to be using. Very few students believed that their instructors were using 'a lot' of the Il, only a quarter or less. Surprisingly, in Language $C$ and $F$ a couple of students thought their instructors were using 'a lot' of English. What is so surprising about this, is that these were the two highest users of the TL with a mean of $92 \%$ or less. This either suggests that the students misunderstood the question or that the instructors used less of the Ll while I was observing.

In two of the six languages, over half of the students felt the instructors used 'some' English. Again, Language $F$ which used a mean of $92 \%$ TL was chosen and Language $E$, which makes more sense, having observed the instructor use a mean of $74 \% \mathrm{TL}$.

The majority of students in four of the languages felt 
the instructor used 'very little' Ll. This seems to match up with the actual percentages of LI use among these instructors, except for Language B which used the highest degrees of L1 at an average of $26 \%$. But because only three students participated in the questionnaire, the results are not conclusive.

Only in one class, Language $c$, was it indicated that the instructor 'never' used the Ll. This is the instructor who used the least L1 so it seems accurate that this be the case. The fourth question addressed students' desired attitudes toward desired English usage by their instructors. The most interesting result is that almost three-quarters of the students for all six languages are satisfied with the amount they are now receiving. This suggests that although the languages that are using high amounts of TL, the students do not seem to be reacting negatively. Perhaps they instead feel challenged. Although a quarter or less of the students either want 'more English than now' or 'less English than now' the majority of the students are satisfied.

The last question asked the students how much of the foreign language they understand in class. Again, over half of the students reported 'understanding most of it'. This seems to be the healthiest. While the students do not understand it all, they are challenged and can understand 
the gist of the foreign language talk. This is really an important realization for students--that not all of the TL needs to be understood because that is an unrealistic goal. Rather, it is a natural and normal process to understand main points of the dialogue and to draw clues from the context. Learners should not be frustrated by the ambiguity that is involved in the language learning process. Only one student, from Language $A$, indicated 'understanding very little' of the teacher's foreign language. This student may have affected the teacher's behavior in regard to language choice. On two classes observed the instructor used higher degrees of LI than usual because of one student's frustration with the language. I am aware that these affective variables may be accounting for how an instructor responds. This case seems to illustrate that student anxiety may influence teacher behavior.

The last part of the questionnaire asked students to comment on anything that was related to foreign language learning. This was used to provide a forum for students to express any opinions or concerns about their class or instructor. Not many students responded, but the comments that were made will be discussed below.

Regarding Language $A$, one student focused on the instructor's spontaneity, commenting that she comes up with 
good ideas off the top of her head to explain new concepts. I observed this on several occasions. She was an energetic instructor who tried to involve her students in a more creative learning process. One other student commented that $s /$ he wished the instructor would go a little slower. This same student though said that $s /$ he understood most of the foreign language the teacher used. Perhaps because she was a native speaker the student had more difficulty keeping up.

For Language $c$ one student made a request that the instructor either write the assignments on the board or explain them in the L1. Because this instructor used the highest amounts of the TL, the student could have been unclear what was required of him/her. One other student commented that although $\mathrm{s} /$ he does not understand all of what is spoken in the foreign language, the instructor's frequent use of the $\mathrm{TL}$ is helpful to learn the language. It is very encouraging to have a student recognize and to applaud his or her instructor's high TL use.

The instructor from Language D, who also was a high user of the TL, had one student make the observation that students often refuse or are too shy to admit that they do not understand what the teacher says. If the teacher asks if the students understand and no one says otherwise, the teacher has no idea that there is confusion. The only 
clues are to be aware of nonverbal signs or to recognize the errors on exams. I was surprised since there seemed to be a good rapport between instructor and students. In this case, I feel the instructor can only do so much and then it is the responsibility of the students.

Language $E$ had the most comments. One student wrote that $s /$ he did not feel adequately prepared for the "level of exactness" the instructor demanded for passing this class, although $\mathrm{s} /$ he had had four previous terms of Languge E. This is alarming considering the high amounts of LI used by the instructor. Another student complained that having to read from the text in English was a waste of time and not relevant to learning a foreign language. Finally, another student commented that there was not enough practical work done in class, ie. class listening, labs, or applied use. S/he was unhappy with the teacher and the teaching method. It seemed the students also noticed and regretted the high use of the LI by the teacher.

Finally, for Language $F$ the students commented that the instructor spoke the language well and that he used the TL often. One other student commented on having enjoyed the class. This instructor seemed to have an enthusiastic and involved class. Though he used high degrees of the TI, the students seemed to enjoy the 
learning process and did not respond negatively.

\section{TEACHER INTERVIEWS}

The teacher interviews were designed to also explore the teachers' perceptions and attitudes regarding the use of the $\mathrm{LI}$ in the foreign language classroom. While the instructors were profiled in the previous chapter, this section will focus more closely on drawing some conclusions and on the teachers' comments.

\section{Language $A$}

This instructor has had a lot of teaching experience which is evident in her control of the class. She said she believed if the Ll was used it should be for purposes of grammar analysis, administrative issues, and upon student demand. Accordingly, that is mainly what she used it for in class. She said she believed in minimal use of the L1-about $10 \%$ of the time. In actuality, she used the Ll about $14 \%$ of the time. This is comparitively close. I think she often did stress the TL, considering the student responses on the questionnaire. I just happened to be observing on days when she was discussing language analysis for the exams which accounted for the higher Ll percentages.

\section{Lanquage $B$}

This instructor used the most LI of all the instructors. She also was the youngest and least 
experienced. Though she admitted that her pronunciation might be a bit of a problem to the students, it did not stop her from using English in the classroom. She said she used the Ll as little as possible, only if necessary. on the contrary, she used it quite frequently. Because she was using her native language teaching to non-native speakers, it may have been more difficult for her to decide how to simplify her classroom discourse for the students. Her overuse of the Ll at the expense of the TL may have been due to her overcompensating. In bilingual research, it has frequently been demonstrated that teachers are unaware of the ratio of their TL/LI use. In addition, among bilingual educators it has been shown that frequently there is an overuse of the language that is not their L1-that there is not a balanced use of the two languages (Legarreta, 1977). She also admitted to being unsure of the best way to teach a language. From our conversation she has not had much training in teaching methodology. Perhaps she would have felt more comfortable and been more prepared had she had more exposure and observation of the other teaching assistants.

\section{Language $C$}

This instructor has been teaching this language for several years. Because he is not a native speaker of language $C$, he recognized the importance of simulating the 
target environment. He used the highest amounts of the TL in his classes and also believed next to no Il should be used. He announced that he only used the Ll for language analysis and vocabulary translation. This was confirmed when calculating the purposes for $L 1$ use. For the most part, he was quite accurate in his perceptions and attitudes in relation to actual practices within the classroom.

\section{Language D}

This instructor, who used a great deal of TL in the classroom, has had much experience teaching Language D. She was different from the other instructors since she was studying within the Linguistics program, and not the Foreign Language program. This may have accounted for her unique approach to language teaching in providing many student oriented activities. She said she believed in exposing the students to the TL using "pro-active" methods and seemed to encourage the students to find language in all facets of everyday life. She commented that she would Iike to not use the LI in the classroom, which was an accurate assessment of herself. She also said she did not like to switch back and forth between the Ll and the TL as it can be confusing for the students. She was not observed doing this. She usually gave the information in the TI and then the Ll if was necessary. 


\section{Language $\mathbf{E}$}

Although this instructor has had a lot of experience teaching Language E, approximately five years, she used an average of $25 \%$ Ll use on the classes observed. In contrast, she reported trying to use the LI as little as possible. She may not have been aware how much it added up, since she often alternated between the two languages. She was one of the only instructors expressing concern for the anxiety students feel about prolonged TL use. Perhaps that is why she so readily used the L1. She was the one instructor who also seemed to be more concerned with grammar, stating that often students do not understand the grammar of their own language.

\section{Language $\mathbf{F}$}

This particular instructor has had the most experience teaching language and has taught to the widest variety of populations. For these reasons, he seems very aware of his students' needs and the different issues they face. He commented that he will not rule out use of the Ll because of the anxiety it can cause learners. Another reason for doing this is that many students may not have had that much exposure to the language. Though he said that, he did use very high degrees of the TL while teaching. Compared to the other instructors, he seemed to touch more upon the cultural aspect of language learning through literature 
which is an important and often neglected area.

\section{SUMMARY}

In conclusion, the languages observed offered insight into the teaching practices utilized by instructors, especially in reference to the issue of language choice. On the basis of my observations, it was unclear that any instructor was ascribing to a particular methodology of foreign language instruction. Rather, eclecticism seemed to preside in the observed classes. Only one instructor, Language $C$, stated that he was an advocate of the proficiency-oriented classroom. He also had the highest TL use. When interviewed, the other instructors admitted to not following any particular methodology.

The question raised is how much does methodology influence language choice? Or, what are the other issues that dictate language choice, especially Ll use? The instructors observed might have chosen to use the LI for affective purposes, to ease the anxiety of their students. The L1 may have been used for saving time and confusion or it may have been a spontaneous, unconscious decision. Perhaps the the choice was influenced by departmental requirements. For the most part, based on the purposes for which the L1 was used and through my observations, it often appeared the rationale for employing the Ll was mainly 
dictated by wanting to save time and was a spontaneous decision. Sometimes the LI was used to prevent student confusion. Yet, it did not seem that the reason for language choice was dictated by the instructor's adherence to any particular methodology. It must be reiterated again that because Language $A$ is not categorized under Group I-those languages easiest to learn and acquire, but instead belongs to Group II, that this may have been a variable in affecting L1 use by instructor. For Group II languages, it takes more hours to reach the same level of proficiency as Group I languages.

Finally, as an observer there did not appear to be much communication between the teaching assistants. There may have been more interaction between the same languages, in regard to testing, but on a whole, it seemed the instructors were using their own approach to language teaching.

\section{LIMITATIONS AND DIFFICULTIES OF STUDY}

One limitation with this investigation was that it may have been frustrating as a reader to not know the identity of the languages involved. This would have proved interesting for readers to make their own conclusions based on the specific language. Yet not having the languages labelled, forced one to see them as similar, based upon the 
fact that all were blanketed under the Indo European languages. It also was necessary to protect the anonymity of the instructors.

Another Iimitation was that there were not enough total students to make any strong generalizations regarding the student questionnaire. Especially concerning Language $B$, with only three students participating. I have some reservations about the questionnaire, in that the use of such quantifiers as 'a lot', 'some', and 'a little' are a bit abstract. What 'a lot' means to one student might mean 'some' to another student. There may be no common consensus on the terms. In future research, the operational definition of amounts must be more specific. Any conclusions drawn must be speculative. An improvement in design of the instrument is necessary.

All of the intructors except one were teaching assistants. For the most part, they all have had a lot of experience. Yet, certain variables may have affected the results of the data such as whether or not the instructors were native speakers, years of teaching experience, class level, or departmental requirements. As was noted by one researcher, (Nunan, 1987, 138):

The classroom speech of foreign language teachers is affected by at least two kinds of constraints: those imposed by the classroom as the setting for 
conversation, including the patterns of speech associated with the role of the teacher, and those arising from the limited proficiency of the interlocutor.

\section{SUGGESTIONS FOR FUTURE RESEARCH}

This investigation was designed and conducted to describe the practices within university-level foreign language classrooms in regard to instructor $\mathrm{Ll}$ and $\mathrm{TL}$ use. It was also conducted to include student and teacher input concerning language choice. It is hoped that the information generated will facilitate communication between the foreign language educators observed by getting them to talk about what goes on within the classroom and improve foreign language services to the learners.

Though more hours were observed for this investigation than the Duff and Polio, it would be interesting to observe over a longer period of time. Perhaps instead of including only second year classes, first year classes could be added as well to make comparisons.

Finally, now that investigations like this are being executed that reveal what transpires within some foreign language classrooms, it would be a contribution to the language teaching profession to do research not on how much L1/TL use there is within the classroom, but rather how the LI/TL use affects student language acquisition. 


\section{REFERENCES}

Akinson, D. (1987). The mother tongue in the classroom: A neglected resource? ELT Journal, 41, 241-247.

Auerbach, E. R. (1993). Reexamining English only in the ESL classroom. TESOL Quarterly, 27, 9-30.

Auerbach, E. R. (1994). The author responds... TESOL Uuarterly, 28, 157-161.

Belasco, S. (1983). Time, proficiency, and the best method: An editorial. Modern Language Journal, 67, 213-215.

Benseler, D. P., \& Schulz, R. A. (1980). Methodological trends in college foreign language instruction. Modern Language Journal, 64, 88-96.

Blair, R. W. (1991). Innovative approaches. In celceMurcia, M. (Ed.) Teaching English as a second or foreign language (pp. 23-45). Massachusetts: Heinle \& Heinle Publishers.

Bloomfield, L. (1942). Outline guide for the practical study of foreign languages. Baltimore: Linguistic Society of America.

Brown, D. H. (1987). Principles of language learning and teaching. Englewood Cliffs, NJ: Prentice Hall, Inc.

Brown, D. H. (1990) - Breaking the language barrier: Creating your own pathway to success. Maine: Intercultural Press, Inc.

Celce-Murcia, M. (1991). Language teaching approaches. In Celce-Murcia, M. (Ed.) Teaching English as a second or foreign language (pp. 3-10). Massachusetts: Heinle \& Heinle Publishers.

Chaudron, C. (1988). Second Language Research: Research on teaching and learning. Cambridge: Cambridge University Press.

Davies, N. F. (1982). Training fluency: An essential factor in language acquisition and use. RELC Journal, 
$13,1-13$

Diller, K. C. (1975). Some new trends for applied linguistics and foreign language teaching in the United States. TESOL Quarterly, 9, 65-73.

Diller, K. C. (1978). The language teaching controversy. Rowley, Massachussets: Newbury House Publishers.

Duff, P. A., \& Polio, C. G. (1990). How much foreign language is there in a foreign language classroom? Modern Language Journal, 74, 154-166.

Ellis, R. (1984). Classroom Second Language Development. Oxford: Pergamon.

Guthrie, E. (1982). Six cases in classroom communication: A study of teacher discourse in the foreign language classroom. In Lantolf, J., \& Labarca, A. (Eds.) Research in SLA: Focus on the classroom (pp. 173193). Norwood, NJ: Ablex

Hosenfeld, C. (1979). A learning-teaching view of second language instruction. Foreign Language Annals, 12, $51-54$.

Kalivoda, T. B. (1983). The priority of conducting FI classes in the target language.Hispania, 66, 573-581.

Kalivoda, T. B. (1988). Teaching a foreign language dominated class. Hispania, 71, 955-958.

Krashen, S. D. (1982). Principles and practices in second language acquisition. Oxford: Pergamon.

Krashen, S. D. (1982). The natural approach: Language acquisition in the classroom. ELT, 38, 217-218.

Legarreta, D. (1977). Language choice in bilingual classrooms. TESOL QuarterIy, 11, 9-16.

Moskowitz, G. (1978). Caring and sharing in the FL class: A source book on humanistic techniques. New York: Newbury House Publishers.

Moskowitz, G. (1976). The classroom interaction of outstandind foreign language teachers. Foreign Language Annals, 9, 135-142. 
Nunan, D. (1987). Communicative language teaching: Making it work. ELT Journal, 41, 136-145.

Nunan, D. (1989). Understanding language classrooms: A guide for teacher-initiated action. New York: Prentice Hall.

Omaggio, A. C. (1983). Methodology in transition: The new focus on proficiency. Modern Language Journal, $67,330-341$.

Omaggio, A. C. (1986). Teaching language in context. Massachusetts: Heinle \& Heinle Publishers.

Polio, C. (1994). Comments on Elsa Auerbach's "Reexamining English only in the ESL classroom". TESOL Quarterly, 28, 153-157.

Politzer, R. L. (1980). Foreign language teaching and bilingual education: Research implications. Foreign Language Annals, 13, 291-297.

Prator, C. H. (1991). Cornerstones of method and names for the profession. In Celce-Murcia, M. (Ed.) Teaching English as a second or foreign language (pp. 11-22). Massachusetts: Heinle \& Heinle Publishers.

Richards, J. C, \& Rodgers, T. S. (1986). Approaches and methods in language teaching. New York: Cambridge University Press.

Shrum, J. L. (1985). Wait-time and the use of target or native languages. Foreign Language Annals, 18, 305312 .

Simon, P. (1980). The tongue-tied American: Confronting the foreign language crisis. New York: Continuum.

Stern, H. H. (1983). Fundamental concepts of language teaching. Iondon: Oxford University Press.

Strasheim, I. (1976). What is a foreign language teacher teacher today? Canadian Modern Language Review, 33, $39-48$.

Swain, M. (1985). Target language use in the wider environment as a factor in acquisition. New Dimensions in SLA research. 
Terrell, T. D. (1982). A natural method. In Blair, R. W. (Ed.) Innovative approaches to language teaching (pp. 160-174). Rowley, MA: Newbury House Publishers.

Warriner, H. P. (1980). Foreign language teaching in the schools--1979: Focus on methodology. Modern Language Journal, 64, 81-96.

Wing, B. H. (1987). The linguistic and communicative functions of foreign language teacher talk. In Vanpatten, B., Dvorak, T. R., \& Lee, J. F. (Eds.) Foreign language learning: A research perspective (pp. 158-173). Cambridge: Newbury House Publishers.

Winitz, H. (1981). The comprehension approach. New York: Newbury House Publishers.

Wong-Fillmore, L. (1985). When does teacher talk work as input? In Scarcella, R. C., \& Long, M. H. (Eds.) Input in second language acquisition (pp. 17-50). Cambridge: Newbury House Publishers.

Wong-Fillmore, L. (1989). Teachability and second language acquisition. In Rice, M. L., \& Schiefelbusch, R. L. (Eds.) The teachability of language (pp. 311-332). Baltimore: Paulh Brooks Publishing Co. 
APPENDIX A

LETTER OF INTRODUCTION 
DATE: 16 December 1994

TO:

FROM: Jeanine Huber

Hello. I am currently enrolled in the MA, TESOL program within the Linguistics Department here at Portland State University. The reason I am writing to you is that I am about to begin my thesis which involves classroom based research. My topic specifically concentrates on the use of language within the foreign language classroom. I would greatly appreciate if I could observe 5 hours of your class. The research would involve audiotaping the lesson, administering a brief student questionnaire ( 5 questions) at the end of the study, and conducting a short teacher interview. I have enclosed a copy of the informed consent form to give you a clearer idea. If you have any questions regarding my research, you can contact my thesis advisor, Kimberley Brown at 725-3566 (NH $451 \mathrm{R}$ ).

If possible, I would like to set up an appointment with you as soon as possible. I can be reached at 222-0216 or I will leave a message on your voice mail. Thank you for your time and happy holiday!

Sincerely, 
APPENDIX B

STUDENT QUESTIONNAIRE 
STUDENT QUESTIONNAIRE

Undergraduate student

Graduate student

Your age:

18-25 years old

$26-35$ $36+$

Your major

This course name

1. Why are you taking this foreign language class? interest requirement major easy other credits

2. Where have you had exposure to this foreign language? Please check all that are relevant.

at home or elsewhere in the local community in the country where the language is spoken previous courses before this academic year no other experience other than the first year course

3. How much English does your teacher typically use in class?

a lot (most of the time) some (some of the very little (occasionally) never

4. How much English would you like your teacher to use in class?

more English than now about the same as now less than now

5. How much of your teacher's foreign language do you understand in class?

all
very little most of it some of it

6. Any related comments? (from Duff \& Polio, 1990, p.165) 
APPENDIX C

TEACHER INTERVIEW 
TEACHER INTERVIEW

TEACHER BACKGROUND:

1. Please tell me about your teaching experience. How long have you been teaching Language $x$ and to what types of populations?

2. Is your background in language teaching, linguistics, or literature?

3. How do you feel about your proficiency in Language $X$ ?

4. Do you feel as comfortable speaking English as you do Language $\mathrm{X}$ when you teach?

5. Do you use the two languages for different things?

PERCEPTION OF STUDENTS' ABILITY:

6. What is your perception of your students' ability in Language $X$ ? 7. When you speak Language $X$, how well do you think your students understand you?

PHILOSOPHY OF TEACHING :

8. Please tell me something about what you believe is the best way to learn and teach a language.

9. What is your opinion on how much English and how much of Language $X$ should be used when you are teaching?

PERCEPTION OF WHY STUDENTS ARE STUDYING LANGUAGE $X$ :

10. Why do you think your students are studying Language $\mathrm{X}$ ?

(from Duff \& Polio, 1990, p. 166) 
APPENDIX D

FIELD NOTES/OBSERVATION FORM 
FIELD NOTES/OBSERVATION FORM

Observer

courese

Date

I. Classroom configuration:

$n=$

II. Activities

time

III. Handouts or other props

IV. Taping/acoustic problems

v. Other problems or comments

(from Duff \& Polio, 1990, p. 165)
Time

Teacher 